\title{
AMBIENTE INSTITUCIONAL, ESTRUTURA DO FUTEBOL FEMININO E DESEMPENHO DE 61 CLUBES DAS LIGAS MAIS FORTES DO MUNDO
}

\author{
Anna Beatriz Grangeiro Ribeiro Maia \\ Doutora em Administração e Controladoria pela Universidade Federal do Ceará \\ Professora da Universidade de Fortaleza \\ abgrmaia@unifor.br
}

\begin{abstract}
Alessandra Carvalho de Vasconcelos Doutora em Engenharia de Produção pela Universidade Federal de Santa Catarina (UFSC) Professora da Universidade Federal do Ceará (UFC) alevasconcelos.ufc@gmail.com
\end{abstract}

\section{Resumo}

Objetivo: Este artigo tem como objetivo analisar os fatores que impulsionam a estrutura do futebol feminino e seu possível reflexo no desempenho dos clubes que participam das ligas mais fortes do mundo.

Método: A amostra foi composta por 61 clubes, de seis nacionalidades, referentes às ligas mais fortes do mundo, na temporada 2017-2018. Empregou-se para coleta de dados a pesquisa documental e análise de conteúdo, e para análise dos dados, a análise fatorial, análise de clusters, estatística descritiva e teste de diferença entre médias.

Originalidade/relevância: $\mathrm{O}$ debate científico sobre estrutura dos clubes e desempenho tem se concentrado em equipes masculinas, não sendo encontrados estudos aplicados ao futebol feminino nessa temática. Do exposto, explora-se tal investigação, na tentativa de contribuir com evidências empíricas iniciais sobre essa questão.

Resultados: Foram identificados três fatores impulsionadores da estrutura do futebol feminino dos clubes, a saber: pressão dos stakeholders, pressão por diversidade e tamanho do clube, em conformidade com as expectativas institucionais. Os resultados indicaram diferenças significantes entre as médias do desempenho operacional dos clubes com e sem estrutura de futebol feminino, não sendo possível identificar diferenças quanto ao desempenho econômico-financeiro.

Contribuições teóricas/metodológicas: Reside na construção do índice geral de estrutura do futebol feminino e na classificação dos clubes, conforme sua estrutura de futebol feminino, e a consequente relação com o desempenho no âmbito dos clubes profissionais.

Contribuições sociais/para a gestão: Sinaliza clubes que apresentam melhor estrutura de futebol feminino que podem servir de benchmarking, orientando ações, políticas e condutas.

Palavras-chave: Fatores institucionais. Futebol feminino. Desempenho.

\section{$\underline{\text { Cite como }}$}

American Psychological Association (APA)

Maia, A. B. G. R., \& de Vasconcelos, A. C. (2022, jan./abr.). Ambiente institucional, estrutura do futebol feminino e desempenho de 61 clubes das ligas mais fortes do mundo. PODIUM Sport, Leisure and Tourism Review, São Paulo, 11(1), 26-58.

https://doi.org/10.5585/podium.v11i1.19066. 


\title{
INSTITUTIONAL ENVIRONMENT, WOMEN'S FOOTBALL STRUCTURE AND PERFORMANCE OF 61 OF THE WORLD'S TOP-LEAGUE SOCCER CLUBS
}

\begin{abstract}
Objective: To evaluate factors bolstering the structure of women's football and their possible impact on performance in the world's top-league soccer clubs.

Methods: The sample included 61 of the world's top-league football clubs from six countries, covering the 2017-2018 season.Data collected by document review and content analysis were submitted to factor analysis, cluster analysis, descriptive statistics and testing for differences between means.

Originality/relevance: Academic discussions on football club structure and performance have been centered exclusively on men's football. Our investigation contributes with novel empirical data on the structure and performance of major women's football clubs.

Results: Three factors were found to have a positive impact on the structure of women's football: stakeholder pressure, pressure for diversity and club size, in accordance with institutional expectations. Clubs with and without women's football structure differed significantly with regard to mean operating performance, but no difference in economic-financial performance was detected.

Methodological/theoretical contributions: Contributions include the building of a general index of women's football structure, the classification of professional clubs according to women's football structure, and the testing for associations between structure and club performance.

Social and management contributions: The clubs with the most successful women's football structure, as identified by the study, may serve as benchmarks, informing future actions, policies and conducts.
\end{abstract}

Keywords: Institutional factors. Women's football. Performance.

\section{AMBIENTE INSTITUCIONAL, ESTRUCTURA DEL FÚTBOL FEMENINO Y DESEMPEÑO DE 61 EQUIPOS DE LAS LIGAS MÁS FUERTES DEL MUNDO}

\section{Resumen}

Objetivo: Analizar los factores que impulsan la estructura del fútbol femenino y su posible impacto en el desempeño de los equipos participantes de las ligas más fuertes del mundo.

Método: La muestra fue compuesta por 61 equipos, de seis nacionalidades, de las ligas más fuertes del mundo, temporada 2017-2018. Se utilizó para la recolección de datos la investigación documental y el análisis de contenido, y para el análisis de datos, el análisis factorial, análisis clúster, estadística descriptiva y prueba de diferencia entre medias.

Originalidad/relevancia: El debate científico sobre estructura de los equipos y desempeño se ha centrado en equipos masculinos, y no se encontraron estudios aplicados al fútbol femenino en esta temática. Por ello, esta investigación intenta contribuir con evidencias empíricas iniciales sobre este tema.

Resultados: Se identificaron tres factores impulsores de la estructura del fútbol femenino de los equipos: presión de los stakeholders, presión por diversidad y tamaño del equipo, conforme las expectativas institucionales. Los resultados indican diferencias significativas entre las medias del desempeño operacional de equipos con y sin estructura de fútbol femenino, pero no fue posible identificar diferencias referentes al desempeño económico y financiero.

Aportes teóricos/metodológicos: Construcción del índice de estructura general del fútbol femenino y clasificación de los equipos, según su estructura de fútbol femenino, y la consecuente relación con el desempeño en el ámbito de los equipos profesionales.

Aportes sociales/para la gestión: Señala a los equipos que presentan mejor estructura de fútbol femenino que pueden servir de benchmarking, orientando acciones, políticas y conductas.

Palabras clave: Factores institucionales. Fútbol feminino. Desempeño. 
Maia, A. B. G. R., \& de Vasconcelos, A. C. (2022, jan./abr.). Ambiente institucional, estrutura do futebol feminino e desempenho de 61 clubes das ligas mais fortes do mundo

\section{Introdução}

Promover a participação de mulheres no futebol passou a compor a agenda de órgãos internacionais do esporte, como a Fédération Internationale de Football Association [FIFA] (2014, 2016), a Confederação Sul-Americana de Futebol [Conmebol] (2016) e a Union of European Football Associations [UEFA] (2017). (Maia \& Vasconcelos, 2020). Contudo, apesar de em alguns países a modalidade apresentar estrutura profissionalizada, nem sempre foi assim. O futebol feminino, em especial, enfrenta diferentes dificuldades e desafios, desde a sua proibição que perdurou por quase todo o século passado.

Não obstante a isso, enquanto taxas de participação e investimentos aumentaram nos últimos 25 anos (FIFA, 2014; UEFA, 2017), alguns atributos institucionais - como demanda consistente de espectadores - que podem ajudar a criar vantagem competitiva sustentável, continuam a ser apontados como desafios estratégicos enfrentados no futebol feminino (Valenti, Scelles \& Morrow, 2019).

Em junho de 2020, a Conmebol decidiu suspender o processo de aplicação de licenças de clubes no futebol feminino como requerimento obrigatório para participar na Conmebol Libertadores Feminina 2020 - que será disputada na Argentina, de 5 a 21 de março de 2021 -, dada a excepcionalidade da situação gerada pela Covid-19 (Conmebol, 2020a). O sistema de licença de clubes é um dos projetos fundamentais na qual a Confederação se baseia para impulsionar a profissionalização do futebol feminino na América do Sul, potenciando assim o âmbito esportivo, financeiro, administrativo, de infraestrutura e jurídico dos diferentes clubes (Conmebol, 2020a).

No contexto do futebol europeu, proprietários (shareholders) e diretores (stakeholders) dos clubes profissionais expressam preocupação com custos crescentes e falta concomitante de receitas (por exemplo, emissão de ingressos e transmissão televisiva) disponíveis para equipes de futebol feminino (European Club Association [ECA], 2014), aumentando o ceticismo sobre a possibilidade de o futebol se tornar financeiramente sustentável em um futuro próximo (Allison, 2016). Contudo, de acordo com as estatísticas, são mais de 29 milhões de mulheres jogando futebol ao redor do mundo, dados estes que dobraram nos últimos 10 anos (Balardin, Voser, Duarte Junior \& Mazo, 2018).

Neste contexto, os países desenvolvidos tratam o futebol feminino de forma profissional e organizada, com um número de praticantes e torcedores elevado - o que representa um retorno financeiro maior aos clubes e às instituições que atendem ao futebol (Radnedge, 2009). Com o 
Maia, A. B. G. R., \& de Vasconcelos, A. C. (2022, jan./abr.). Ambiente institucional, estrutura do futebol feminino e desempenho de 61 clubes das ligas mais fortes do mundo

crescente interesse pelo futebol feminino, o varejo mostra uma tendência semelhante aos recordes de audiência: a Nike, por exemplo, relata que camisas da seleção feminina norteamericana são as mais vendidas de todos os tempos, entre homens e mulheres (Torres, 2019). Esses dados exprimem relevância e potencialidade econômica ao futebol feminino mundial.

Sob a mesma ótica, a FIFA avalia que nos próximos anos o aumento da receita para torneios de mulheres crescerá muito e, para não perder o protagonismo no comando dos torneios mundiais, apresentou ideia de criar um Mundial de Clubes feminino (Rizzo, 2020). O presidente da FIFA, Gianni Infantino, diz que o Mundial entraria no borderô de US\$ 1 bilhão que a federação pretende investir no futebol feminino até 2022 (Rizzo, 2020). O projeto seria de que o torneio fosse anual ou a cada dois anos, para fortalecer o crescimento da modalidade.

Por outro lado, em países subdesenvolvidos como o Brasil, o futebol feminino ainda é praticado de forma amadora, uma vez que a maioria das atletas desenvolve outras atividades profissionais (Balardin, Voser, Duarte Junior \& Mazo, 2018). O investimento no futebol feminino brasileiro é pequeno e com pouca visibilidade tanto de público como da mídia em geral (Sardinha, 2011). Segundo Alves (2019), no país, somente em 2019 os clubes profissionais passaram a (i) cumprir as exigências da Confederação Brasileira de Futebol [CBF] e (ii) possuir equipes femininas - e ainda assim, não necessariamente as atletas são recursos controlados pelo clube. Alguns clubes fizeram parcerias com clubes amadores para fornecimento de uniforme, campo para treino e estrutura mínima, mas sem arcar com custos com as atletas (Alves, 2019).

Em aposta ao desenvolvimento e profissionalização do futebol feminino sul-americano, o presidente da Conmebol, Alejandro Domínguez, realizou vários anúncios durante seu discurso de abertura do Congresso Futebol com F de Feminino que aconteceu em dezembro de 2020, tais como: a Conmebol Copa América Feminina passará a ser disputada a cada dois anos a partir de 2022; a Conmebol propõe a criação da Copa Intercontinental entre clubes femininos; a Conmebol exonerará o pagamento de Licenças Pro de treinadoras a todas as mulheres durante três anos (Conmebol, 2020b).

A estrutura financeira dos clubes de futebol feminino, na prática, assemelha-se à dos clubes amadores masculinos, cujas principais fontes de renda vêm de doações e investimentos privados, com uma contribuição muito menos substancial do prêmio em dinheiro e receitas de bilheteria e transmissão de jogos (ECA, 2014; Fédération Internationale des Associations de Footballeurs Professionnels [FIFPro], 2017). Portanto, ante a necessidade de geração de mais receitas de todas as fontes (Valenti, Scelles \& Morrow, 2019), identificar fatores institucionais 
Maia, A. B. G. R., \& de Vasconcelos, A. C. (2022, jan./abr.). Ambiente institucional, estrutura do futebol feminino e desempenho de 61 clubes das ligas mais fortes do mundo

que favorecem a criação de vantagem competitiva, e por sua vez, incrementam o desempenho aos clubes de futebol é crucial para a sustentabilidade corporativa do futebol feminino.

Argumentos teóricos apontam uma relação entre os distintos atributos internos, bem como diferentes fontes e níveis de pressão externa, sustentados pelos mecanismos de isomorfismo enraizados na Teoria Institucional (Dimaggio \& Powell, 1983). Somados a isso, fundamentos da Visão Baseada em Recursos - RBV, do inglês Resource-based View (Barney, 1991; Penrose, 1959; Rumelt, 1984; Wernerfelt, 1984) defendem o ponto de vista de que a vantagem competitiva é derivada de sua capacidade de montar e explorar uma combinação adequada dos seus recursos.

$\mathrm{Na}$ literatura, considera-se que a representação feminina é especialmente importante para a obtenção de vantagem competitiva (Dezsö \& Ross, 2012; Green \& Homroy, 2018). Especificamente quanto ao mercado futebolístico, este debate tem se concentrado nas equipes masculinas (Costa, Costa, Angelo \& Moraes, 2018; Szymanski, Fitzsimmons \& Danis, 2019), não sendo encontrados estudos aplicados ao futebol feminino. Destarte, um foco peculiar foi definido com amparo nas contribuições de estudos recentes sobre futebol feminino, oriundos de disciplinas sociológicas (Balardin, Voser, Duarte Junior \& Mazo, 2018; McLachlan, 2019) e econômicas (Klein, 2018; Kringstad, 2018; Valenti, Scelles \& Morrow, 2019).

Diante do exposto, esta pesquisa identificou como lacuna primordial a ser explorada a identificação dos fatores incentivadores à estrutura do futebol feminino, em clubes profissionais das ligas mais fortes do mundo. Ademais, também foram encontradas lacunas quanto ao possível reflexo desta estrutura do futebol feminino na performance dos clubes profissionais.

Destarte, em face do contexto do estudo, e considerando as lacunas citadas, este artigo procura responder às seguintes questões: Que fatores impulsionam a estrutura do futebol feminino dos clubes? E quais os possíveis reflexos da estrutura do futebol feminino no desempenho dos clubes?

A partir dessas questões, e com base em uma pesquisa realizada em clubes profissionais das ligas mais fortes do mundo, na temporada 2017-2018 (IFFHS, 2019), procurou-se analisar os fatores que impulsionam a estrutura do futebol feminino e seu possível reflexo no desempenho. Para atingi-lo, foram perseguidos os seguintes objetivos específicos: (i) identificar os fatores institucionais que impulsionam a estrutura de futebol feminino dos clubes profissionais; (ii) construir o índice geral de estrutura do futebol feminino e classificar os clubes profissionais, conforme sua estrutura de futebol feminino; (iii) comparar o desempenho operacional e econômico-financeiro dos clubes com e sem estrutura de futebol feminino. 
Maia, A. B. G. R., \& de Vasconcelos, A. C. (2022, jan./abr.). Ambiente institucional, estrutura do futebol feminino e desempenho de 61 clubes das ligas mais fortes do mundo

Visando atender o critério de ineditismo, esta pesquisa investiga duas partes específicas do futebol feminino que se complementam. A primeira esquadrinha padrões de isomorfismo institucional com suporte na identificação dos fatores que impulsionam a estrutura (física e econômico-financeira) de futebol feminino dos clubes profissionais - em alinhamento ao primeiro e segundo objetivos específicos. A segunda esmiúça os reflexos do índice geral de estrutura do futebol feminino criado no desempenho dos clubes profissionais - em atendimento ao terceiro objetivo específico.

Ressalta-se que, embora atratividade e competitividade (Hallmann, 2012; Hallmann, Oshimi, Harada, Matsuoka \& Breuer 2016; Klein, 2004; Lefeuvre, Stephenson \& Walcott, 2013; Meier; Leinwather, 2012; Schallhorn, Knoll \& Schramm, 2017) representem algumas das principais questões que os shareholders lutam para superar, até hoje poucas publicações em economia esportiva investigaram empiricamente a causalidade entre fatores que impulsionam o desenvolvimento do futebol feminino (Valenti, Scelles \& Morrow, 2019), tal como proposto na presente pesquisa, tendo em vista a atualidade da temática.

Portanto, este estudo exploratório busca obter uma melhor compreensão da estrutura do futebol feminino e seu reflexo no desempenho dos clubes, na tentativa de contribuir com evidências empíricas iniciais sobre essa questão, a partir de uma amostra de 61 clubes, de seis nacionalidades (Argentina, Brasil, Espanha, França, Inglaterra e Itália), que fazem parte das ligas mais fortes do mundo - Nível 4, conforme ranking do Club World Ranking (CWR) 2018 - TOP 400, da International Federation of Football History \& Statistics [IFFHS] (2019), na temporada 2017-2018.

\section{Fundamentação teórica e desenvolvimento das hipóteses}

Várias teorias econômicas são empregadas para estudos direcionados ao futebol masculino, como: Teoria da Agência (Maia, Rebouças, Vasconcelos \& Reinaldo, 2018); Teoria dos Stakeholders (Siqueira, Pajanian \& Telles, 2015); Teoria dos Custos de Transação (Martins, Marquezan, Diehl \& Flores, 2017); Visão Baseada em Recursos (Costa, Costa, Angelo \& Moraes, 2018; Galvão \& Dornelas, 2017); e Teoria Institucional (Allison, 2016; Arakelian, Brito \& Rosenthal, 2020; Dias \& Rossi, 2017; Maia \& Cardoso, 2019; Mayer, Martins, \& Kronbauer, 2017).

Esta pesquisa está fundamentada em duas teorias econômicas principais: Teoria Institucional e Visão Baseada em Recursos (RBV). A primeira no tocante aos padrões de 
Maia, A. B. G. R., \& de Vasconcelos, A. C. (2022, jan./abr.). Ambiente institucional, estrutura do futebol feminino e desempenho de 61 clubes das ligas mais fortes do mundo

isomorfismo institucional com suporte na identificação dos fatores que impulsionam a estrutura de futebol feminino dos clubes profissionais. A segunda quanto aos reflexos da estrutura de futebol feminino no desempenho, comparando o desempenho operacional e econômicofinanceiro dos clubes profissionais em função da estrutura de futebol feminino.

A Teoria Institucional tem raízes econômicas (Coase, 1937; North, 1990; Williamson, 1985) e sociais (Dimaggio \& Powell, 1983; Meyer \& Rowan, 1977; Scott, 1995; Selznick, 1948). A aplicação inicial da Teoria Institucional às organizações esportivas é atribuída a Slack (Cousens \& Slack, 2005; Slack, 1994). Refletindo a tendência em direção a análises isomórficas no início do novo trabalho institucional, um dos principais focos da pesquisa de Slack (1994) tem sido em processos pelos quais as organizações esportivas se tornam mais sintonizadas com seus ambientes e se parecem mais semelhantes umas às outras ao longo do tempo (Allison, 2016).

Os esportes são administrados de forma variada por lógicas institucionais comerciais, de entretenimento, educacionais, amadoras e profissionais, entre outras. No entanto, a maioria das pesquisas sobre os ambientes institucionais das organizações esportivas tem se concentrado nos esportes masculinos (Allison, 2016). Destarte, os clubes de futebol podem ser afetados por diferentes mecanismos institucionais de isomorfismo (coercitivo, normativo, mimético), a partir de atributos internos ou pressões externas.

Como exemplos de atributos internos das entidades desportivas, podem ser citados: Natureza jurídica, referente à sua forma jurídica (associação, sociedade limitada ou sociedade anônima de capital aberto); Finalidade econômica (com ou sem fins lucrativos); Endividamento (Faria, Dantas, \& Azevedo, 2019; Pereira, Brunozi Junior, Kronbauer, \& Abrantes, 2015); Porte (Schaefer, Fagundes, Moraes, Nara, \& Kothe, 2019), Representatividade feminina na alta gestão (Galbreath, 2018; Terjesen, Aguilera, \& Lorenz, 2015).

Também podem ser citadas pressões externas exercidas por diversas instituições sobre as entidades desportivas, como as provenientes de: Confederação de vínculo (AFC; CAF, CONCACAF; CONMEBOL; UEFA) (Barbosa, Dantas, Azevedo, \& Holanda, 2017; Torgler, 2008); Liga nacional masculina que o clube participa (Faria, Dantas, \& Azevedo, 2019; Valenti, Scelles, \& Morrow, 2019); Hegemonia do futebol masculino nacional, referente à pontuação equivalente à classificação na FIFA da seleção nacional masculina de futebol respectiva ao clube (Torgler, 2008); País-sede de eventos da FIFA, referente ao número de realizações de Torneios FIFA (Copa do Mundo) no respectivo país; Economia nacional ao qual o clube pertence (país desenvolvido ou emergente) (Rohde \& Breuer, 2018; Torgler, 2008); 
Maia, A. B. G. R., \& de Vasconcelos, A. C. (2022, jan./abr.). Ambiente institucional, estrutura do futebol feminino e desempenho de 61 clubes das ligas mais fortes do mundo

Internacionalização do clube, a partir de atletas estrangeiros (Pyatunin et al., 2016; Rohde \& Breuer, 2018; Xu, 2018).

Assim, com base nos argumentos oferecidos pela literatura ainda incipiente sobre futebol feminino (Klein, 2018; Kringstad, 2018; Valenti, Scelles, \& Morrow, 2019), pelos estudos sobre o futebol masculino que guardam harmonia em relação a este (Dias \& Rossi, 2017), e em conformidade com as expectativas institucionais (Dimaggio \& Powell, 1983), a primeira hipótese da pesquisa pondera que: $H_{1}$ : $O$ ambiente institucional afeta a estrutura de futebol feminino dos clubes.

Para testar a primeira hipótese, considerando os atributos internos dos clubes, são definidas cinco hipóteses operacionais baseadas em: Finalidade econômica (Dimaggio \& Powell, 1983), Natureza jurídica (Dimaggio \& Powell, 1983), Endividamento (Faria, Dantas, \& Azevedo, 2019; Pereira, Brunozi Junior, Kronbauer, \& Abrantes, 2015), Porte (Schaefer, Fagundes, Moraes, Nara \& Kothe, 2019) e Representatividade feminina na alta gestão (Galbreath, 2018; Terjesen, Aguilera \& Lorenz, 2015). Ademais, considerando as pressões externas sobre os clubes, são definidas seis hipóteses operacionais baseadas em: Confederação de vínculo (Torgler, 2008), Nível da Liga masculina (Faria, Dantas, \& Azevedo, 2019), Economia nacional (Rohde \& Breuer, 2018; Torgler, 2008), Quantidade de Torneios FIFA realizados pelo respectivo país (Torgler, 2008), Hegemonia do futebol masculino nacional (Markovits \& Hellerman, 2003; Torgler, 2008) e Internacionalização de atletas no clube (Pyatunin et al., 2016; Rohde \& Breuer, 2018; Xu, 2018).

Em sua maioria, os estudos prévios seguem os trabalhos clássicos de Rottenberg (1956) e Scully (1974) e veem o funcionamento dos clubes de futebol profissional como um processo de produção, que transforma insumos esportivos (trabalho e capital) em produtos (atendimento, receita e sucesso no campo de futebol). Neste estudo, a função objetiva "verdadeira" dos clubes está entre a maximização da vitória e a do lucro (Feng \& Jewell, 2018). Neste sentido, a Visão Baseada em Recursos (RBV) pode ajudar a compreender de que forma a estrutura do futebol feminino pode refletir no desempenho dos clubes.

Penrose (1959), considerada como pioneira da RBV, avalia todos os recursos internos disponíveis como parte dos fatores para o crescimento das firmas. Assim, o crescimento das empresas é determinado pelas características de gestão e capacidade de aprendizado com os recursos disponíveis (internos) (Wernerfelt, 1984), específicos e não replicáveis (Barney, 1991), e os recursos requeridos (externos). Pode-se concluir que dentre estes recursos, os intangíveis representam uma parcela significativa. 
Maia, A. B. G. R., \& de Vasconcelos, A. C. (2022, jan./abr.). Ambiente institucional, estrutura do futebol feminino e desempenho de 61 clubes das ligas mais fortes do mundo

Diante do exposto, na presente pesquisa, considera-se que a partir dos ativos intangíveis, mais especificamente dos Direitos federativos dos atletas, é possível identificar o desempenho operacional dos clubes de futebol. Dessa forma, são considerados os seguintes indicadores do desempenho operacional dos clubes: Performance do capital humano, calculada a partir da razão entre Receitas de transferências e Direitos federativos dos atletas (Maia \& Cardoso, 2019; Ricci, Scafarto, Celenza, \& Gilvari, 2015) e Performance do capital relacional e estrutural, calculada a partir da razão entre Receitas operacionais, excluindo transferências, e o valor residual do Ativo Total após deduzidos Direitos federativos dos atletas (Maia \& Cardoso, 2019; Ricci, Scafarto, Celenza, \& Gilvari, 2015).

De modo semelhante, os ativos intangíveis contribuem para o desempenho econômicofinanceiro dos clubes de futebol, ao passo em que compõem o ativo total e o patrimônio total dessas organizações. Como exemplos de proxies utilizadas comumente para verificar o desempenho econômico-financeiro dos clubes de futebol tem-se: Retorno sobre o Ativo (ROA), calculado a partir da razão entre o Lucro Operacional e o Ativo Total (Faria, Dantas, \& Azevedo, 2019; Pereira, Brunozi Junior, Kronbauer, \& Abrantes, 2015); e, Retorno sobre o Patrimônio Líquido (ROE), calculado a partir da razão entre o Lucro Líquido e o Patrimônio Líquido (Faria, Dantas, \& Azevedo, 2019; Pereira, Brunozi Junior, Kronbauer, \& Abrantes, 2015).

Sob essa linha de pensamento científico, investimentos em futebol feminino podem ser relevantes no âmbito dos clubes profissionais, incluindo ou transformando seus recursos humanos em valiosos, raros, com dificuldade de serem imitados e de serem substituídos. À luz da RBV, investimentos em futebol feminino podem ser utilizados como estratégia dos dirigentes e gestores no âmbito dos clubes profissionais de utilização de seus recursos, tornando-os valiosos, raros, difíceis de imitar e de serem substituídos, incrementando o desempenho dos clubes no mercado tão competitivo como o do futebol.

Nessa lógica, os clubes profissionais poderão ter incrementos de receitas com novos patrocínios, vendas de artigos exclusivos ao público feminino, transmissão de jogos etc. Por conseguinte, os departamentos comercial e de marketing dos clubes devem tratar o futebol feminino como um produto diferenciado - avalia Nina de Abreu, coordenadora de futebol feminino do Atlético-MG (Costa \& Fonseca, 2019).

Também com assento nos argumentos oferecidos pela literatura pertinente (Klein, 2018; Kringstad, 2018; Valenti, Scelles, \& Morrow, 2019), estudos sobre o futebol masculino que guardam harmonia relativamente a este (Costa, Costa, Angelo, \& Moraes, 2018; Maia \& 
Maia, A. B. G. R., \& de Vasconcelos, A. C. (2022, jan./abr.). Ambiente institucional, estrutura do futebol feminino e desempenho de 61 clubes das ligas mais fortes do mundo

Vasconcelos, 2016; Mayer, 2017), e sob a égide da RBV (Barney, 1991; Penrose, 1959; Rumelt, 1984; Wernerfelt, 1984), a segunda hipótese alça que: $\mathrm{H}_{2}$ : Clubes com estrutura de futebol feminino possuem desempenho superior aos clubes sem estrutura de futebol feminino.

Para testar a segunda hipótese, considerando as diferentes naturezas do desempenho dos clubes, são definidas duas hipóteses operacionais baseadas em: Desempenho operacional e Desempenho econômico-financeiro. Tem-se que, as atletas, consideradas como recursos estratégicos humanos são utilizados para o sucesso competitivo dos clubes, no que tange às suas habilidades, experiências e capacidades, gerando benefícios operacionais e econômicos (Galvão \& Dornelas, 2017). Espera-se ainda que, na análise referente ao desempenho econômico-financeiro, o efeito seja positivo, pois indica que os clubes podem obter uma rentabilidade positiva associada à sua atividade operacional (Faria, Dantas, \& Azevedo, 2019).

Assim, consolida-se o delineamento das hipóteses operacionais da pesquisa, defendendo a interlocução entre os construtos ambiente institucional, futebol feminino e desempenho (Figura 1).

Figura 1.

Modelo Operacional de Análise

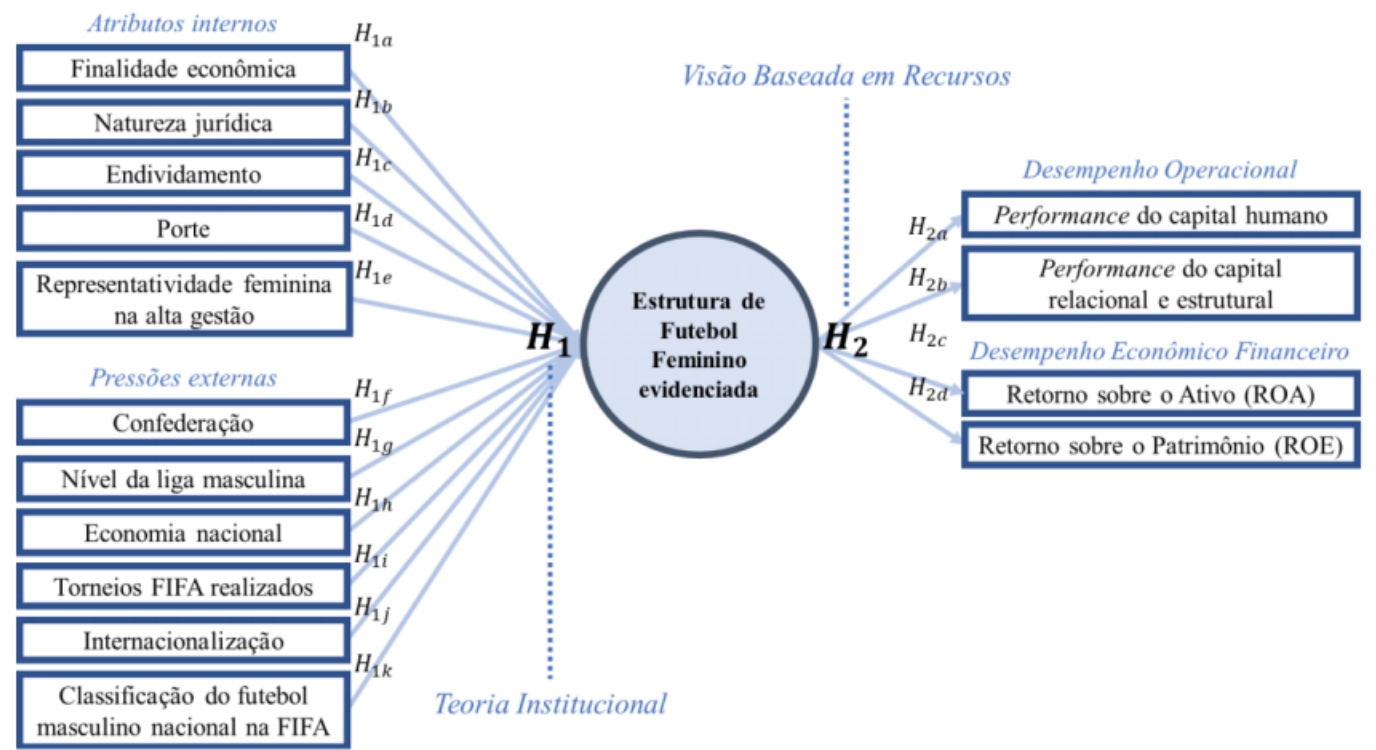

Fonte: Elaborado pelos autores.

A seção seguinte aborda a trajetória metodológica percorrida no estudo de modo a atender os objetivos delineados, a fim de responder às questões de pesquisa. 
Maia, A. B. G. R., \& de Vasconcelos, A. C. (2022, jan./abr.). Ambiente institucional, estrutura do futebol feminino e desempenho de 61 clubes das ligas mais fortes do mundo

\section{Procedimentos metodológicos}

Quanto à estratégia de pesquisa, o estudo exploratório se baseia primariamente no exame de arquivos, com esteio em indicadores secundários coletados por meio de busca documental, ao empregar dados disponíveis nos websites, estatutos, relatórios anuais e demonstrações financeiras dos clubes de futebol profissionais.

Em procedimento semelhante ao adotado em outros estudos (Maia \& Vasconcelos, 2016; Nascimento, Nossa, Bernardes, \& Sousa, 2015), a população da pesquisa reúne os clubes de futebol mais fortes do mundo ranqueados pelo Club World Ranking (CWR) 2018 - TOP 400, da Federação Internacional de História e Estatísticas do Futebol - em inglês International Federation of Football History \& Statistics (IFFHS), que mensura o desempenho desportivo em torneios nacionais e internacionais.

Para definição da amostra não probabilística, foi considerado como principal critério a disponibilização dos relatórios anuais, referente ao exercício de 2017-2018, em seus portais eletrônicos oficiais. A delimitação temporal se dá essencialmente por dois motivos: (1) a FIFA e algumas associações regionais (UEFA, CONMEBOL) passaram a exigir que clubes de futebol profissionais que disputam seus campeonatos oficiais possuam equipes femininas a partir de 2017; (2) o ano de 2018 equivale ao último exercício social encerrado e com informações divulgadas pelos clubes nos meses de dezembro de 2019 e janeiro de 2020, período de coleta dos dados da pesquisa. Assim, no estudo, foram consideradas as informações divulgadas pelos clubes profissionais sobre a sua estrutura (física e econômico-financeira) de futebol feminino na temporada 2017-2018.

Cabe ressaltar que apesar de trabalhos anteriores sobre clubes de futebol masculino terem considerado um lapso temporal maior, sob o enfoque da RBV (Benin, 2017) e do ativo intangível como recurso estratégico (Ricci, Scafarto, Celenza, \& Gilvari, 2015), esta pesquisa apresenta como uma de suas limitações o acesso aos dados, tendo em vista que o futebol feminino tem passado do amadorismo, ou mesmo inexistência em muitos dos clubes analisados, para o profissionalismo ou semiprofissionalismo a partir de 2017-2018 (temporada analisada). Considerando o exposto, a amostra é composta por clubes que fazem parte do Nível 4, do ranqueamento do IFFHS (2019), que pertencem às ligas mais fortes do mundo, totalizando 61 clubes profissionais, de seis nacionalidades (argentinos, brasileiros, espanhóis, franceses, ingleses e italianos). 
Maia, A. B. G. R., \& de Vasconcelos, A. C. (2022, jan./abr.). Ambiente institucional, estrutura do futebol feminino e desempenho de 61 clubes das ligas mais fortes do mundo

Para a identificação dos fatores institucionais que impulsionam a estrutura de futebol feminino dos clubes profissionais, o Quadro 1 apresenta as variáveis dos constructos atributos internos e pressões externas, com operacionalização e suporte teórico.

\section{Quadro 1.}

Variáveis Referentes ao Ambiente Institucional

\begin{tabular}{|c|c|c|}
\hline \multicolumn{3}{|c|}{ ATRIBUTOS INTERNOS } \\
\hline Variáveis & Operacionalização & Suporte teórico \\
\hline Natureza jurídica & $\begin{array}{l}\text { Variável categórica, medida em escala nominal (1: } \\
\text { associação sem fins lucrativos; } 2 \text { : sociedade limitada; } \\
\text { 3: sociedade anônima de capital aberto) }\end{array}$ & \multirow[t]{2}{*}{$\begin{array}{l}\text { Dimaggio \& Powell (1983) } \\
\text { Hall \& Soskice }(2001)\end{array}$} \\
\hline Finalidade econômica & $\begin{array}{l}\text { Dummy, medida em escala nominal (1: com fins } \\
\text { lucrativos; 0: demais) }\end{array}$ & \\
\hline Endividamento & $\begin{array}{l}\text { Variável quantitativa, calculada a partir da razão entre } \\
\text { Passivo Total e Ativo Total }\end{array}$ & $\begin{array}{c}\text { Faria, Dantas, \& Azevedo } \\
\text { (2019) } \\
\text { Pereira, Brunozi Junior, } \\
\text { Kronbauer, \& Abrantes } \\
\text { (2015) }\end{array}$ \\
\hline Porte & $\begin{array}{l}\text { Variável quantitativa, medida em escala de razão, } \\
\text { referente ao Ativo Total normalizado }\end{array}$ & $\begin{array}{l}\text { Schaefer, Fagundes, Moraes, } \\
\text { Nara, \& Kothe (2019) }\end{array}$ \\
\hline $\begin{array}{l}\text { Representatividade } \\
\text { feminina na alta } \\
\text { gestão }\end{array}$ & $\begin{array}{l}\text { Variável quantitativa, medida em escala de razão, } \\
\text { referente ao total de mulheres na alta gestão }\end{array}$ & $\begin{array}{l}\text { Galbreath (2018) } \\
\text { Terjesen, Aguilera, \& } \\
\text { Lorenz (2015) }\end{array}$ \\
\hline \multicolumn{3}{|c|}{ PRESSÕES EXTERNAS } \\
\hline Variáveis & Operacionalização & Suporte teórico \\
\hline $\begin{array}{l}\text { Confederação de } \\
\text { vínculo }\end{array}$ & $\begin{array}{l}\text { Variável categórica, medida em escala nominal, } \\
\text { referente à associação que o clube é subordinado (1: } \\
\text { AFC; 2: CAF; 3: CONCACAF; 4: CONMEBOL; 5: } \\
\text { UEFA) }\end{array}$ & $\begin{array}{l}\text { Barbosa, Dantas, Azevedo, } \\
\text { \& Holanda (2017) } \\
\text { Torgler }(2008)\end{array}$ \\
\hline $\begin{array}{l}\text { Nível da liga } \\
\text { masculina }\end{array}$ & $\begin{array}{l}\text { Variável quantitativa, ordinal, referente ao nível da } \\
\text { liga nacional que o clube participa, com base na } \\
\text { IFFHS (1: mais fraco; } 4 \text { : mais forte) }\end{array}$ & $\begin{array}{l}\text { Faria, Dantas, \& Azevedo } \\
\text { (2019) } \\
\text { Valenti, Scelles, \& Morrow } \\
(2019)\end{array}$ \\
\hline Economia nacional & $\begin{array}{l}\text { Dummy, medida em escala nominal, referente ao } \\
\text { desenvolvimento do mercado econômico nacional (1: } \\
\text { país desenvolvido; 0: país emergente) }\end{array}$ & $\begin{array}{l}\text { Rohde \& Breuer }(2018) \\
\text { Torgler }(2008)\end{array}$ \\
\hline $\begin{array}{l}\text { Torneios } \quad \text { FIFA } \\
\text { realizados }\end{array}$ & $\begin{array}{l}\text { Variável quantitativa, medida em escala de razão, } \\
\text { referente ao número de realizações de Torneios FIFA } \\
\text { (Copa do Mundo) no respectivo país }\end{array}$ & Torgler (2008) \\
\hline $\begin{array}{l}\text { Internacionalização } \\
\text { de atletas }\end{array}$ & $\begin{array}{l}\text { Variável quantitativa, referente ao número médio de } \\
\text { atletas estrangeiras no período }\end{array}$ & $\begin{array}{c}\text { Pyatunin et al. (2016) } \\
\text { Rohde \& Breuer (2018) } \\
\text { Xu (2018) }\end{array}$ \\
\hline $\begin{array}{l}\text { Classificação } \\
\text { nacional do futebol } \\
\text { masculino na FIFA }\end{array}$ & $\begin{array}{l}\text { Variável quantitativa, referente à pontuação } \\
\text { equivalente à classificação na FIFA da seleção } \\
\text { nacional masculina de futebol respectiva ao clube }\end{array}$ & Torgler (2008) \\
\hline
\end{tabular}

Fonte: Elaborado pelos autores.

Os dados referentes ao ambiente institucional foram extraídos dos relatórios contábilfinanceiros disponibilizados pelos clubes, à exceção de Liga masculina, Economia nacional, Quantidade de Torneios FIFA e Internacionalização de atletas no clube, que foram coletados, 
Maia, A. B. G. R., \& de Vasconcelos, A. C. (2022, jan./abr.). Ambiente institucional, estrutura do futebol feminino e desempenho de 61 clubes das ligas mais fortes do mundo

respectivamente, a partir das bases: IFFHS (https://www.iffhs.com/), United Nations (2018), FIFA (https://www.fifa.com/) e Transfermarkt (https://www.transfermarkt.com/).

Quanto à estrutura do futebol feminino, com base nos resultados de Balardin, Voser,

Duarte Junior e Mazo (2018), que compararam o futebol feminino no Brasil e nos Estados Unidos, nesta pesquisa é construído um índice específico que considera as informações disponibilizadas pelos clubes sobre a estrutura física e econômico-financeira. Assim, as proxies consideradas no constructo estrutura do futebol feminino, com base em Ricci, Scafarto, Celenza e Gilvari (2015), são apresentadas no Quadro 2.

Quadro 2.

Variáveis Referentes à Estrutura do Futebol Feminino

\begin{tabular}{|c|c|}
\hline \multicolumn{2}{|r|}{ Categoria: estrutura física } \\
\hline Variáveis & Operacionalização \\
\hline WBWC & $\begin{array}{l}\text { Dummy, medida em escala nominal, referente ao ranking feminino The World's Best } \\
\text { Woman Club } 2018 \text { da IFFHS (1: está presente; 0: não está presente) }\end{array}$ \\
\hline Idade & $\begin{array}{l}\text { Variável quantitativa, medida em uma escala de razão, indicando quantos anos possui o } \\
\text { futebol feminino no clube de forma contínua, desde a sua implementação até } 2020\end{array}$ \\
\hline Maturidade & $\begin{array}{l}\text { Dummy, medida em escala nominal, indicando se o clube implementou o futebol feminino } \\
\text { antes de } 2015 \text { ou não, isto é, se apresenta } 5 \text { ou mais anos fomentando o desenvolvimento } \\
\text { ininterrupto do futebol feminino (1: apresenta; 0: não apresenta) }\end{array}$ \\
\hline Elenco & $\begin{array}{l}\text { Dummy, medida em escala nominal, referente à existência de uma equipe principal } \\
\text { feminina em 2017-2018 (1: apresenta; 0: não apresenta) }\end{array}$ \\
\hline Categorias de base & $\begin{array}{l}\text { Variável quantitativa, medida em uma escala de razão, indicando o número de categorias } \\
\text { de base para o futebol feminino no clube }\end{array}$ \\
\hline $\begin{array}{l}\text { Centro de } \\
\text { treinamento }\end{array}$ & $\begin{array}{l}\text { Dummy, medida em escala nominal, referente à existência de centro de treinamento para } \\
\text { atletas do futebol feminino (1: apresenta; 0: não apresenta) }\end{array}$ \\
\hline Academia & $\begin{array}{l}\text { Dummy, medida em escala nominal, referente à existência de academia de } \\
\text { formação/educação para atletas do futebol feminino (1: apresenta; 0: não apresenta) }\end{array}$ \\
\hline Salário & $\begin{array}{l}\text { Dummy, medida em escala nominal, referente à evidenciação de salários para as atletas do } \\
\text { futebol feminino (1: apresenta; 0: não apresenta) }\end{array}$ \\
\hline Convocações & $\begin{array}{l}\text { Dummy, medida em escala nominal, referente à existência de convocação de atletas do } \\
\text { clube para as suas seleções nacionais (1: apresenta; } 0 \text { : não apresenta) }\end{array}$ \\
\hline Seleções nacionais & $\begin{array}{l}\text { Dummy, medida em escala nominal, referente à evidenciação de número de seleções que } \\
\text { convocaram suas atletas (1: apresenta; 0: não apresenta) }\end{array}$ \\
\hline $\begin{array}{l}\text { Atletas } \\
\text { convocadas }\end{array}$ & $\begin{array}{l}\text { Dummy, medida em escala nominal, referente à evidenciação específica do número de } \\
\text { atletas convocadas para as respectivas seleções nacionais (1: apresenta; } 0 \text { : não apresenta) }\end{array}$ \\
\hline Suporte médico & $\begin{array}{l}\text { Variável quantitativa, referente à evidenciação de quantidade de especialidades médicas } \\
\text { que o clube fornece de suporte às atletas }\end{array}$ \\
\hline Gestão própria & $\begin{array}{l}\text { Dummy, medida em escala nominal, referente à existência de gestão própria do futebol } \\
\text { feminino (1: apresenta; 0: não apresenta ou é realizada em forma de parcerias) }\end{array}$ \\
\hline $\begin{array}{l}\text { Unidade geradora de } \\
\text { caixa (UGC) }\end{array}$ & $\begin{array}{l}\text { Dummy, medida em escala nominal, referente à percepção do futebol feminino como } \\
\text { Unidade Geradora de Caixa - UGC (1: apresenta; 0: não apresenta) }\end{array}$ \\
\hline
\end{tabular}


Maia, A. B. G. R., \& de Vasconcelos, A. C. (2022, jan./abr.). Ambiente institucional, estrutura do futebol feminino e desempenho de 61 clubes das ligas mais fortes do mundo

\begin{tabular}{|c|c|}
\hline \multicolumn{2}{|r|}{ Categoria: estrutura econômico-financeira } \\
\hline Var & Operacionalização \\
\hline $\begin{array}{l}\text { Investimentos no } \\
\text { futebol feminino }\end{array}$ & $\begin{array}{l}\text { Dummy, medida em escala nominal, referente à evidenciação de investimentos referentes } \\
\text { ao futebol feminino (1: apresenta; 0: não apresenta) }\end{array}$ \\
\hline Ati & $\begin{array}{l}\text { Dummy, medida em escala nominal, referente à evidenciação do ativo intangível referente } \\
\text { ao futebol feminino (1: apresenta; 0: não apresenta) }\end{array}$ \\
\hline $\mathrm{R}$ & $\begin{array}{l}\text { Dummy, medida em escala nominal, referente à evidenciação de receitas referentes ao } \\
\text { futebol feminino (1: apresenta; 0: não apresenta) }\end{array}$ \\
\hline Cus & $\begin{array}{l}\text { Dummy, medida em escala nominal, referente à evidenciação de custos referentes ao } \\
\text { futebol feminino (1: apresenta; 0: não apresenta) }\end{array}$ \\
\hline $\begin{array}{r}\text { Receita op } \\
\text { bruta }(1\end{array}$ & $\begin{array}{l}\text { Dummy, medida em escala nominal, referente à evidenciação do lucro bruto referente ao } \\
\text { futebol feminino (1: apresenta; 0: não apresenta) }\end{array}$ \\
\hline Despesas gerais & $\begin{array}{l}\text { Dummy, medida em escala nominal, referente à evidenciação das despesas gerais referentes } \\
\text { ao futebol feminino (1: apresenta; 0: não apresenta) }\end{array}$ \\
\hline Folh & $\begin{array}{l}\text { Dummy, medida em escala nominal, referente à evidenciação da folha de pagamento } \\
\text { referente ao futebol feminino (1: apresenta; 0: não apresenta) }\end{array}$ \\
\hline $\begin{array}{l}\text { Despesa com } \\
\text { auditores }\end{array}$ & $\begin{array}{l}\text { Dummy, medida em escala nominal, referente à evidenciação de despesa com auditores } \\
\text { referente ao futebol feminino (1: apresenta; 0: não apresenta) }\end{array}$ \\
\hline Amorti & $\begin{array}{l}\text { Dummy, medida em escala nominal, referente à evidenciação de amortizações referentes } \\
\text { ao futebol feminino (1: apresenta; 0: não apresenta) }\end{array}$ \\
\hline Depr & $\begin{array}{l}\text { Dummy, medida em escala nominal, referente à evidenciação de depreciações referentes ao } \\
\text { futebol feminino (1: apresenta; 0: não apresenta) }\end{array}$ \\
\hline Outras Despesas & $\begin{array}{l}\text { Dummy, medida em escala nominal, referente à evidenciação de outras despesas referentes } \\
\text { ao futebol feminino (1: apresenta; 0: não apresenta) }\end{array}$ \\
\hline $\begin{array}{c}\text { Resultado } \\
\text { operacional líquido } \\
\text { (ROL) }\end{array}$ & $\begin{array}{l}\text { Dummy, medida em escala nominal, referente à evidenciação do resultado operacional } \\
\text { líquido referente ao futebol feminino (1: apresenta; 0: não apresenta) }\end{array}$ \\
\hline Transferências & $\begin{array}{l}\text { Dummy, medida em escala nominal, referente à evidenciação do resultado com } \\
\text { transferências referente ao futebol feminino (1: apresenta; 0: não apresenta) }\end{array}$ \\
\hline Resultado financeiro & $\begin{array}{l}\text { Dummy, medida em escala nominal, referente à evidenciação do resultado financeiro } \\
\text { referente ao futebol feminino (1: apresenta; 0: não apresenta) }\end{array}$ \\
\hline $\begin{array}{l}\text { Lucro antes dos juros } \\
\text { e tributos (EBIT) }\end{array}$ & $\begin{array}{l}\text { Dummy, medida em escala nominal, referente à evidenciação do EBIT referente ao futebol } \\
\text { feminino (1: apresenta; 0: não apresenta) }\end{array}$ \\
\hline Impostos e taxas & $\begin{array}{l}\text { Dummy, medida em escala nominal, referente à evidenciação de impostos e taxas referentes } \\
\text { ao futebol feminino (1: apresenta; 0: não apresenta) }\end{array}$ \\
\hline $\begin{array}{l}\text { Resultado líquido do } \\
\text { exercício }\end{array}$ & $\begin{array}{l}\text { Dummy, medida em escala nominal, referente à evidenciação do resultado líquido do } \\
\text { exercício referente ao futebol feminino (1: apresenta; 0: não apresenta) }\end{array}$ \\
\hline
\end{tabular}

Fonte: Elaborado pelos autores.

Vale ressaltar que os dados da estrutura física e econômico-financeira foram extraídos dos relatórios contábil-financeiros disponibilizados pelos clubes da amostra, especificamente sobre o futebol feminino. Ou seja, foram consideradas as informações econômico-financeiras dos clubes que evidenciaram especificamente tais valores quanto à sua estrutura de futebol feminino. Portanto, clubes que forneceram informações apenas de forma geral, não pontuaram no check-list.

Assim, foram construídos os seguintes indicadores: Índice de Estrutura do Futebol Feminino - Estrutura Física (IEFF-F), calculado com base no somatório das 14 variáveis 
referente à categoria Estrutura Física; Índice de Estrutura do Futebol Feminino - Estrutura Econômico-Financeira (IEFF-EF), calculado com base no somatório das 17 variáveis referente à categoria Estrutura Econômico-Financeira; e Índice de Estrutura do Futebol Feminino (IEFF), calculado com base no somatório de todas as 31 variáveis referentes à estrutura do futebol feminino.

O desempenho dos clubes profissionais da amostra foi analisado a partir das dimensões operacional e econômico-financeira. O Quadro 3 apresenta as quatro proxies referentes aos respectivos desempenhos, seguidas da operacionalização e suporte teórico.

Quadro 3.

Variáveis Referentes ao Desempenho

\begin{tabular}{|c|c|c|}
\hline \multicolumn{3}{|c|}{ DESEMPENHO OPERACIONAL } \\
\hline Variáveis & Operacionalização & \multirow{3}{*}{$\begin{array}{c}\text { Suporte teórico } \\
\text { Maia \& Cardoso (2019) } \\
\text { Ricci, Scafarto, Celenza, \& } \\
\text { Gilvari (2015) }\end{array}$} \\
\hline $\begin{array}{l}\text { Performance do capital } \\
\text { humano }(\mathrm{PCH})\end{array}$ & $\begin{array}{l}\text { Razão entre Receitas de transferências e } \\
\text { Direitos federativos dos atletas }\end{array}$ & \\
\hline $\begin{array}{l}\text { Performance do capital } \\
\text { relacional e estrutural } \\
\text { (PCRE) }\end{array}$ & $\begin{array}{l}\text { Razão entre Receitas operacionais, } \\
\text { excluindo transferências, e o valor residual } \\
\text { do Ativo Total após deduzidos Direitos } \\
\text { federativos dos atletas }\end{array}$ & \\
\hline \multicolumn{3}{|c|}{ DESEMPENHO ECONÔMICO-FINANCEIRO } \\
\hline Variáveis & Operacionalização & Suporte teórico \\
\hline $\begin{array}{l}\text { Retorno sobre Ativos } \\
\text { (ROA) }\end{array}$ & $\begin{array}{l}\text { Razão entre o Lucro Operacional e o Ativo } \\
\text { Total }\end{array}$ & $\begin{array}{c}\text { Faria, Dantas, \& Azevedo (2019) } \\
\text { Maia (2013) }\end{array}$ \\
\hline $\begin{array}{c}\text { Retorno sobre o } \\
\text { Patrimônio Líquido (ROE) }\end{array}$ & $\begin{array}{l}\text { Razão entre o Lucro Líquido e o Patrimônio } \\
\text { Líquido }\end{array}$ & $\begin{array}{c}\text { Pereira, Brunozi Junior, } \\
\text { Kronbauer, \& Abrantes (2015) }\end{array}$ \\
\hline
\end{tabular}

Fonte: Elaborado pelos autores.

Os dados secundários foram coletados por meio da pesquisa documental e processados por meio da análise de conteúdo para a investigação dos fatores institucionais (Quadro 1) que impulsionam a estrutura de futebol feminino dos clubes profissionais, sua categorização e mensuração do índice de estrutura do futebol feminino - IEFF (Quadro 2). Após o refinamento dos dados tabulados, para destes realizar a análise exploratória, uni e multivariada, recorreu-se ao software de análise estatística SPSS®.

Inicialmente, a análise foi realizada a partir da verificação sobre se os atributos internos e pressões externas (itens da escala) impulsionam o índice de estrutura do futebol feminino, aplicando-se a análise fatorial (AF). Para analisar a carga fatorial de cada variável em relação aos componentes extraídos, verifica-se a matriz de componentes. Para evitar o problema de indeterminação da relação entre variáveis e fatores, a mesma variável não pode contribuir para a construção de fatores distintos. Com o objetivo de facilitar a visualização da variação das 
Maia, A. B. G. R., \& de Vasconcelos, A. C. (2022, jan./abr.). Ambiente institucional, estrutura do futebol feminino e desempenho de 61 clubes das ligas mais fortes do mundo

variáveis observadas e os fatores extraídos, utiliza-se o Varimax, que é um método de rotação ortogonal que minimiza o número de variáveis que cada agrupamento terá, simplificando a interpretação dos fatores.

Em seguida, foi realizada classificação dos 61 clubes da amostra, por meio da análise de clusters (AC) hierárquica, seguido pela $\mathrm{AC}$ não hierárquica, sendo complementada pela análise de variâncias (ANOVA). Inicialmente, realizou-se a AC hierárquica, a fim de identificar o número de clusters ideal. A partir da matriz de proximidade (dissimilaridade) foi realizado o método aglomerativo para ordenar as observações nos respectivos clusters, utilizando o método da menor distância (single linkage) para verificar medidas de semelhança e dissemelhança entre as variáveis referentes à estrutura de futebol feminino dos clubes.

Por conseguinte, foi constituído o Índice de Estrutura do Futebol Feminino - IEFF de cada clube no período analisado, bem como suas subcategorias (Estrutura Física, IEFF-F, e Estrutura Econômico-Financeira, IEFF-EF). Na sequência, foram comparados os índices de estrutura do futebol feminino dos clubes (IEFF) e suas subcategorias, por meio da estatística descritiva e do teste-T de amostras independentes. Considerando o Teorema do Limite Central, não foi necessário a verificação do pressuposto de normalidade das distribuições para aplicação do teste. Assim, foi aplicado o teste T para as diferenças de médias, a fim de verificar se o grupo 1 (clubes que possuem equipe de futebol feminino) e o grupo 2 (clubes que não possuem equipe de futebol feminino) apresentam diferenças estatisticamente significantes no que tange ao desempenho operacional e econômico-financeiro (Quadro 3).

Destarte, espera-se atender ao objetivo geral ao investigar os fatores institucionais que impulsionam a estrutura de futebol feminino dos clubes profissionais, bem como seu reflexo no desempenho operacional e econômico-financeiro destes.

\section{Resultados}

\section{Análise dos fatores que impulsionam a estrutura do futebol feminino dos clubes}

Inicialmente, utilizou-se todas as variáveis quantitativas ao mesmo tempo para examinar a matriz de correlações na análise fatorial (AF) exploratória a fim de comprovar se, efetivamente, é pertinente realizar a AF criando fatores que expliquem melhor simultaneamente todas as variáveis representativas do ambiente institucional - atributos internos e pressões externas (Quadro 1). 
Maia, A. B. G. R., \& de Vasconcelos, A. C. (2022, jan./abr.). Ambiente institucional, estrutura do futebol feminino e desempenho de 61 clubes das ligas mais fortes do mundo

A escolha dos fatores institucionais que, em um primeiro momento, ficariam fora da $\mathrm{AF}$ foi facilitada pela matriz de anti-imagem, que indica o poder de explicação dos fatores em cada uma das variáveis analisadas. Apesar de algumas variáveis possuírem pouca relação com os fatores, a maioria dos indicadores conseguiu (na tentativa com todos os indicadores) um poder de explicação alto considerando todos os fatores obtidos (comunalidades) e alguns apresentaram explicações razoáveis (abaixo de 0,70). Com relação à Variância Total Explicada, apesar da fraca relação entre os fatores e algumas variáveis, o modelo consegue explicar $76,317 \%$ da variância dos dados originais, o que é muito bom.

Retirados os fatores da análise (Porte do clube e Internacionalização de atletas) foi realizada uma segunda tentativa para se obter uma AF satisfatória. Contudo, apesar do teste de KMO (MSA) ter melhorado (0.606), ocorreu uma piora significativa no poder de explicação do modelo de algumas variáveis (Endividamento do clube e Representatividade feminina na alta gestão), bem como uma queda de explicação do modelo (Variância Total Explicada de $57,709 \%$, perda de $18,608 \%$ no poder de explicação do modelo em relação à primeira $\mathrm{AF}$ exploratória).

Como a perda de explicação foi significativa, e levando em consideração que existem alguns indicadores com uma baixa correlação entre os fatores, fez-se uma nova análise na matriz de anti-imagem para verificar se existiam fatores que poderiam estar prejudicando a análise. Contudo, a análise da matriz de anti-imagem não demonstrou a presença de outro indicador com explicação abaixo de 0.50. Assim, foram considerados os três fatores retidos (com autovalor superior a 1) que explicam cerca de $76,317 \%$ da variabilidade total, da primeira AF exploratória. Para os fatores extraídos, a percentagem de variância de cada variável explicada pelos valores comuns é superior a $63 \%$ para todas as variáveis.

A Figura 2 ilustra os três fatores criados (componente em espaço rotacionado) a partir da $\mathrm{AF}$, com base na matriz dos fatores rotacionada. 
Figura 2.

Análise Fatorial

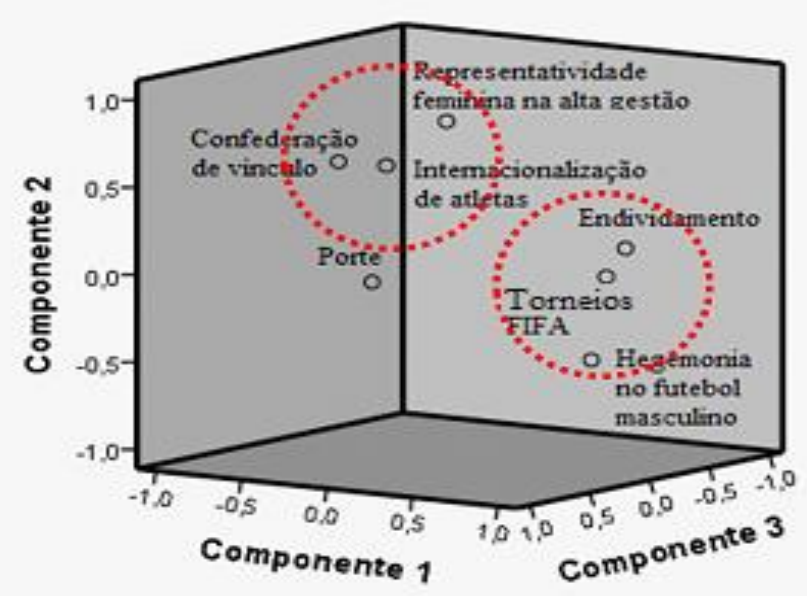

Fonte: Dados da pesquisa.

Na Figura 2, as variáveis analisadas são posicionadas conforme a sua carga fatorial nos componentes extraídos após a rotação, sendo nomeados pelos autores os fatores criados a partir da AF como: (1) Pressão dos stakeholders, composto pelas variáveis Endividamento, Hegemonia no futebol masculino e Torneios FIFA realizados; (2) Pressão por diversidade, composto pelas variáveis Representatividade feminina na alta gestão, Confederação de vínculo e Internacionalização de atletas; (3) Tamanho do clube, composto pela variável Porte.

Tal resultado não permite rejeitar a primeira hipótese do estudo $\left(H_{1}: O\right.$ ambiente institucional afeta a estrutura de futebol feminino dos clubes), tendo em vista que confirma a relação entre os distintos atributos internos (Endividamento, Porte e Representatividade feminina na alta gestão) e pressões externas (Confederação de vínculo, Torneios FIFA, Hegemonia no futebol masculino e Internacionalização de atletas), sustentados pelos mecanismos de isomorfismo institucional (Dimaggio \& Powell, 1983), que impulsionam a estrutura de futebol feminino dos clubes.

\section{Estrutura do futebol feminino dos clubes}

A partir da análise de clusters (AC) hierárquica e análise de variâncias (ANOVA) oneway, observou-se o agrupamento em três clusters $\left(\mathrm{R}^{2}=0,9051\right)$ como a melhor solução das observações referentes à estrutura de futebol feminino dos 61 clubes profissionais. Destarte, procedeu-se à AC não hierárquica, agrupando os clubes em três clusters. 
Maia, A. B. G. R., \& de Vasconcelos, A. C. (2022, jan./abr.). Ambiente institucional, estrutura do futebol feminino e desempenho de 61 clubes das ligas mais fortes do mundo

O cluster 1, denominado Estrutura de futebol feminino madura, é constituído por 18 clubes: FC Barcelona, Liverpool FC, Chelsea FC, Arsenal FC, Manchester City FC, Tottenham Hotspur, Olympique Lyonnais, Villarreal CF, RCD Espanyol, Brighton \& Hove Albion, Athletic Club Bilbao, West Ham United FC, SD Eibar, Levante UD, Everton FC, Real Sociedad, Crystal Palace FC e Newcastle United FC. Este primeiro cluster, que compõe 29,5\% dos clubes da amostra corrobora a literatura (Klein, 2018; Kringstad, 2018; Valenti, Scelles, \& Morrow, 2019), no tocante ao destaque europeu quanto ao elevado nível de desenvolvimento do futebol feminino.

O cluster 2, denominado Estrutura de futebol feminino em desenvolvimento, é formado por 40 clubes: Atlético de Madrid, Real Madrid CF, Juventus FC, SE Palmeiras, Sevilla FC, Grêmio FBPA, Cruzeiro EC, Manchester United FC, Atalanta BC, AS Roma, SSC Napoli, Clube Athletico Paranaense, AC Milan, CR Flamengo, SC Corinthians, Santos FC, Racing Club, Valencia CF, CR Vasco da Gama, Real Betis, EC Bahia, Fluminense FC, São Paulo FC, Botafogo FR, Deportivo Alavés, SC Internacional, Atlético-MG, FC Burnley, CCAA Getafe CF, CD Leganés, Leicester City FC, RC Celta de Vigo, Gimnasia La Plata, AFC Bournemouth, Chapecoense, CA Vélez Sarsfield, Ceará SC, CA Newell's Old Boys, Watford FC e Sport CR. Cabe ressaltar que os referidos clubes apresentam equipes femininas recentes ou ainda não possuem equipes femininas formalizadas, bem como há pouca ou nenhuma informação divulgada pelos referidos clubes sobre a estrutura de futebol feminina. Este segundo cluster, que compõe a maioria dos clubes da amostra (65,57\%), corrobora o apontado pela literatura (Balardin, Voser, Duarte Junior, \& Mazo, 2018), quanto ao futebol feminino sul-americano estar em um estágio amador de desenvolvimento.

O cluster 3, denominado Estrutura de futebol feminino imatura, é constituído por três clubes: SS Lazio, Torino FC e FC Southampton. Os referidos clubes ficaram isolados em um único agrupamento por apresentarem estrutura de futebol feminino com mais tradição (todos com idade acima de 39 anos de atividade), contudo há pouca ou nenhuma informação disponibilizada sobre a estrutura física e econômico-financeira de futebol feminina.

Com base na ANOVA, verificou-se que das 31 variáveis analisadas referentes à estrutura do futebol feminino dos clubes (Quadro 2), apenas seis (19\%) não apresentaram significância estatística quanto à discriminação entre os clusters: quatro variáveis compõem a categoria Estrutura Física (Salário, Seleções nacionais, Atletas convocadas e Suporte médico) e duas variáveis que compõem a categoria Estrutura Econômico-Financeira (Investimentos e Resultado financeiro). 
Maia, A. B. G. R., \& de Vasconcelos, A. C. (2022, jan./abr.). Ambiente institucional, estrutura do futebol feminino e desempenho de 61 clubes das ligas mais fortes do mundo

Dentre as 25 variáveis que apresentaram significância estatística quanto à discriminação entre os clusters, destacam-se: Idade, Maturidade e Gestão própria do futebol feminino (variáveis compõem a categoria Estrutura Física), com Z acima de 30,0; e, ROB, Despesas, ROL e EBIT (variáveis compõem a categoria Estrutura Econômico-Financeira), com Z acima de 13,0 .

A Tabela 1 apresenta o ranqueamento dos 10 clubes com maior índice geral de estrutura do futebol feminino (IEFF). Como pode ser observado, os três clubes com maior pontuação são Manchester City FC (IEFF: 58; IEFF-F: 43; IEFF-EF: 15), Liverpool FC (IEFF: 54; IEFF-F: 39; IEFF-EF: 15) e FC Southampton (IEFF: 54; IEFF-F: 54; IEFF-EF: 0). Os três clubes são ingleses, o que sinaliza o pioneirismo da Inglaterra em todas as modalidades deste esporte.

Tabela 1.

Top 10+ do Índice de Estrutura do Futebol Feminino (IEFF)

\begin{tabular}{c|l|c|c|c}
\hline Top & Clube & IEFF & IEFF-F & IEFF-EF \\
\hline $1^{\mathbf{o}}$ & Manchester City FC & 58 & 43 & 15 \\
\hline $2^{\mathbf{o}}$ & Liverpool FC & 54 & 39 & 15 \\
\hline $3^{\mathbf{o}}$ & FC Southampton & 54 & 54 & 0 \\
\hline $4^{\mathbf{o}}$ & SS Lazio & 52 & 50 & 2 \\
\hline $5^{\mathbf{0}}$ & Arsenal FC & 51 & 41 & 10 \\
\hline $6^{\mathbf{0}}$ & West Ham United FC & 48 & 37 & 11 \\
\hline $7^{\mathbf{0}}$ & Chelsea FC & 47 & 34 & 9 \\
\hline $8^{\mathbf{o}}$ & Brighton \& Hove Albion & 44 & 35 & 2 \\
\hline $9^{\mathbf{0}}$ & RCD Espanyol & 43 & 41 & 0 \\
\hline $10^{\mathbf{o}}$ & Torino FC & 43 & 43 & \\
\hline
\end{tabular}

Nota: IEFF: Índice de Estrutura do Futebol Feminino; IEFF-F: Índice de Estrutura do Futebol Feminino - Estrutura Física; IEFF-EF: Î́ndice de Estrutura do Futebol Feminino - Estrutura Econômico-Financeira.

Fonte: Dados da pesquisa.

Cabe ressaltar também que estes três primeiros clubes possuem empresas controladas que se destinam às atividades específicas de futebol feminino (Manchester City Women Football Club Limited, Liverpool Ladies Football Club Limited e Southampton Girls and Women's Football Club Limited, respectivamente), o que facilitou a identificação das informações coletadas. Contudo, destaca-se que apesar disso, o FC Southampton não apresentou os dados econômico-financeiros considerados na avaliação da estrutura do futebol feminino (IEFF-EF: 0).

Considerando a amostra do estudo, apesar de alguns clubes apresentarem muitas informações quanto a sua estrutura de futebol feminino de uma forma geral, adverte-se que apenas 16 apresentaram informações no que diz respeito ao IEFF-EF. Ou seja, 74\% dos clubes analisados ( $\mathrm{n}=45)$ não apresentaram dados econômico-financeiros sobre o futebol feminino. Tal 
Maia, A. B. G. R., \& de Vasconcelos, A. C. (2022, jan./abr.). Ambiente institucional, estrutura do futebol feminino e desempenho de 61 clubes das ligas mais fortes do mundo

resultado corrobora a recente transposição do amadorismo do futebol feminino para a sua profissionalização, por pressão do ambiente institucional (Allison, 2016; Conmebol, 2016; FIFA, 2014, 2016; UEFA, 2017).

Adicionalmente, a estatística descritiva permite observar o comportamento dos índices de estrutura do futebol feminino dos 61 clubes analisados. $\mathrm{O}$ índice que apresentou menor desvio padrão e variância foi o IEFF-EF, sinalizando também que é baixo o nível de apresentação dos dados econômico-financeiros das equipes de futebol feminino pelos clubes.

No que diz respeito à categoria Estrutura Física referente ao futebol feminino, cabe ressaltar que 20 dos 61 clubes não apresentaram equipe feminina no período investigado (20172018), contudo, 16 apresentaram informações sobre a estrutura física, tendo em vista que desenvolveram suas equipes até 2019, e, portanto, foram considerados para a análise.

Por outro lado, quatro clubes não apresentaram qualquer informação, tendo em vista que até 31 de janeiro de 2020, data final da coleta de dados da pesquisa, não possuíam equipes femininas. São estes: Real Madrid CF, CCAA Getafe CF, RC Celta de Vigo, espanhóis; e, Atalanta BC, italiano.

Ademais, cabe apontar que apesar de serem os clubes com maior IEFF-F, SS Lazio $\left(1^{\circ}\right)$, FC Southampton $\left(2^{\circ}\right)$, Torino FC $\left(4^{\circ}\right)$, e terem uma considerável idade quanto ao tempo de futebol feminino, estes clubes apresentaram alguns aspectos incipientes em sua estrutura de futebol feminino, como a não participação no WBWC e a não apresentação de Centro de treinamento, Academia/Educação, Salário, Convocações e Suporte médico para atletas. Tal resultado pode explicar o agrupamento do cluster 3, denominado Estrutura de futebol feminino imatura constituído por esses três clubes.

É importante informar que, quando suprimido a idade de existência do futebol feminino, destacam-se com melhor Estrutura Física do futebol feminino: o francês, Olympique Lyonnais (11); os ingleses, Crystal Palace FC (11) e Manchester City FC (10); e, o espanhol, RCD Espanyol (10).

No tocante à categoria Estrutura Econômico-Financeira, apenas 16 clubes (26,23\% da amostra) apresentaram alguma das 17 informações investigadas no estudo. Ou seja, 45 clubes (73,77\% da amostra) não apresentaram qualquer informação de natureza econômico-financeira sobre o futebol feminino. Cabe destacar que, destes, 20 clubes não possuíam equipes femininas de futebol no período analisado (2017/2018). Alguns destes informaram, contudo, que voltaram a investir no futebol feminino em 2018, como é o caso do Manchester United. O clube reativou a equipe feminina apenas em 2018 (Manchester United Women's Football Club Limited, 
Maia, A. B. G. R., \& de Vasconcelos, A. C. (2022, jan./abr.). Ambiente institucional, estrutura do futebol feminino e desempenho de 61 clubes das ligas mais fortes do mundo

Private limited Company, Incorporated on 31 May 2018 https://beta.companieshouse.gov.uk/), iniciando no segundo nível do jogo profissional (FA Women's Championship) a partir da temporada 2018/2019. O objetivo do clube é desenvolver uma equipe capaz de competir no mais alto nível no jogo feminino, com um núcleo formado por jogadoras que se formaram no Manchester United Girls' Regional Talent Club (informações retiradas do Relatório Anual - Formulário 20-F).

Quanto aos clubes que mais apresentaram informações econômico-financeiras, destacase a representatividade dos clubes ingleses. Dos 16 clubes que apresentaram informações neste aspecto, oito clubes (50\%) são da Inglaterra: Manchester City FC, Liverpool FC, Chelsea FC, West Ham United FC, Arsenal FC, Everton FC, Brighton \& Hove Albion, e Leicester City FC. Tal representatividade pode ser explicada em virtude do fato de que todos os clubes ingleses investem no futebol feminino e possuem uma empresa própria para gerencia-lo.

Ademais, os clubes ingleses têm apresentado outras informações como o Relatório adicional Gender Pay Data, em conformidade ao Equality Act 2010 (Gender Pay Gap Information) Regulations 2017 - que exige tais informações de grandes empresas (com 250 ou mais funcionários) no Reino Unido (mas não na Irlanda do Norte). Não há exigência legal para empregadores menores reportarem dados, mas são incentivados a fazê-lo.

\section{Reflexos da estrutura do futebol feminino no desempenho dos clubes}

A Tabela 2 apresenta a estatística descritiva das variáveis de desempenho operacional (PCH e PCRE) e econômico-financeiro (ROA e ROE), dos clubes que informaram que possuem equipes femininas em 2017-2018 e dos demais.

\section{Tabela 2.}

Estatística Descritiva das Variáveis de Desempenho dos Clubes de Futebol

\begin{tabular}{l|c|c|c|c|c|c}
\hline \multicolumn{2}{c|}{$\begin{array}{c}\text { Variáveis do } \\
\text { desempenho }\end{array}$} & $\begin{array}{c}\text { Possui equipe feminina } \\
\text { em 2017-2018 }\end{array}$ & N & Média & Desvio Padrão & Erro padrão da média \\
\hline \multirow{2}{*}{$\begin{array}{l}\text { Desempenho } \\
\text { operacional }\end{array}$} & PCH & Sim & 41 & 0,7251 & 1,1884 & 0,1856 \\
\cline { 2 - 6 } & \multirow{2}{*}{ PCRE } & Não & 20 & 5,2789 & 20,0834 & 4,4907 \\
\hline \multirow{2}{*}{$\begin{array}{l}\text { Desempenho } \\
\text { econômico- } \\
\text { financeiro }\end{array}$} & \multirow{2}{*}{ ROA } & Sim & 41 & 1,0918 & 0,7553 & 0,1179 \\
\cline { 2 - 6 } & \multirow{2}{*}{ ROE } & Não & 20 & 1,1133 & 1,2186 & 0,2724 \\
\cline { 2 - 6 } & Sim & 41 & 0,0574 & 0,1611 & 0,0251 \\
\hline Nota: PCH: Pão & 20 & 0,0393 & 0,1299 & 0,0290 \\
\hline
\end{tabular}

Nota: PCH: Performance do capital humano; PCRE: Performance do capital relacional e estrutural; ROA: Retorno sobre Ativos; ROE: Retorno sobre o Patrimônio Líquido.

Fonte: Dados da pesquisa. 
Maia, A. B. G. R., \& de Vasconcelos, A. C. (2022, jan./abr.). Ambiente institucional, estrutura do futebol feminino e desempenho de 61 clubes das ligas mais fortes do mundo

Observa-se que os clubes que possuem equipe feminina em 2017-2018 obtiveram desempenho econômico-financeiro médio superior aos clubes que não possuem, tanto em relação ao ROA quanto ao ROE. Por outro lado, diferente do esperado, clubes com equipe feminina apresentaram desempenho operacional médio inferior, tanto em relação à PCH quanto à PCRE.

A Tabela 3 expõe os resultados do Teste-T de amostras independentes, comparando as distribuições das variáveis de desempenho dos clubes que possuem equipes femininas em 20172018 e daqueles que não possuem.

Tabela 3.

Teste-T de Amostras Independentes

\begin{tabular}{|c|c|c|c|c|c|c|c|c|c|c|}
\hline & \multicolumn{2}{|c|}{$\begin{array}{l}\text { Teste de } \\
\text { Levene }\end{array}$} & \multicolumn{7}{|c|}{ Teste-T para Igualdade de Médias } \\
\hline & & \multirow[t]{2}{*}{$\mathbf{Z}$} & \multirow[t]{2}{*}{ Sig. } & \multirow[t]{2}{*}{$\mathbf{t}$} & \multirow[t]{2}{*}{ df } & \multirow[t]{2}{*}{$\begin{array}{c}\text { Sig. (2 } \\
\text { extrem.) }\end{array}$} & \multirow[t]{2}{*}{$\begin{array}{l}\text { Diferença } \\
\text { média }\end{array}$} & \multirow{2}{*}{$\begin{array}{c}\text { Erro } \\
\text { padrão de } \\
\text { diferença }\end{array}$} & \multicolumn{2}{|c|}{$\begin{array}{c}\text { 95\% Intervalo de } \\
\text { Confiança da } \\
\text { Diferença }\end{array}$} \\
\hline & & & & & & & & & Inferior & Superior \\
\hline \multirow[t]{2}{*}{$\overline{\mathrm{PCH}}$} & $\begin{array}{l}\text { Variâncias } \\
\text { iguais } \\
\text { assumidas }\end{array}$ & 7,927 & 0,007 & $-1,460$ & 59 & 0,150 & $-4,553$ & 3,119 & $-10,796$ & 1,689 \\
\hline & $\begin{array}{l}\text { Variâncias } \\
\text { iguais não } \\
\text { assumidas }\end{array}$ & & & $-1,013$ & 19,065 & 0,324 & $-4,553$ & 4,494 & $-13,958$ & 4,851 \\
\hline \multirow[t]{2}{*}{ PCRE } & $\begin{array}{l}\text { Variâncias } \\
\text { iguais } \\
\text { assumidas }\end{array}$ & 0,813 & 0,371 & $-0,085$ & 59 & 0,933 & $-0,021$ & 0,253 & $-0,529$ & 0,486 \\
\hline & $\begin{array}{l}\text { Variâncias } \\
\text { iguais não } \\
\text { assumidas }\end{array}$ & & & $-0,072$ & 26,349 & 0,943 & $-0,021$ & 0,296 & $-0,631$ & 0,588 \\
\hline \multirow[t]{2}{*}{ ROA } & $\begin{array}{l}\text { Variâncias } \\
\text { iguais } \\
\text { assumidas }\end{array}$ & 0,135 & 0,715 & 0,438 & 59 & 0,663 & 0,018 & 0,041 & $-0,064$ & 0,101 \\
\hline & $\begin{array}{l}\text { Variâncias } \\
\text { iguais não } \\
\text { assumidas }\end{array}$ & & & 0,472 & 45,919 & 0,639 & 0,018 & 0,038 & $-0,059$ & 0,095 \\
\hline \multirow[t]{2}{*}{ ROE } & $\begin{array}{l}\text { Variâncias } \\
\text { iguais } \\
\text { assumidas }\end{array}$ & 0,329 & 0,569 & 0,507 & 59 & 0,614 & 0,736 & 1,453 & $-2,171$ & 3,644 \\
\hline & $\begin{array}{l}\text { Variâncias } \\
\text { iguais não } \\
\text { assumidas }\end{array}$ & & & 0,653 & 57,883 & 0,516 & 0,736 & 1,128 & $-1,521$ & 2,995 \\
\hline
\end{tabular}

Nota: PCH: Performance do capital humano; PCRE: Performance do capital relacional e estrutural; ROA: Retorno sobre Ativos; ROE: Retorno sobre o Patrimônio Líquido.

Fonte: Output do SPSS.

Conforme observado na Tabela 3, os resultados do Teste-T de amostras independentes revelaram que há diferenças estatisticamente significantes $($ sig. $=0,007)$ apenas entre as médias 
Maia, A. B. G. R., \& de Vasconcelos, A. C. (2022, jan./abr.). Ambiente institucional, estrutura do futebol feminino e desempenho de 61 clubes das ligas mais fortes do mundo

da variável PCH, sendo as médias dos clubes que possuem equipe feminina em 2017-2018 inferior $(-4,553)$ aos clubes que não possuem.

Tal resultado, que parece refutar os pressupostos da RBV (Barney, 1991; Penrose, 1959; Rumelt, 1984; Wernerfelt, 1984) - os ativos intangíveis podem influenciar positivamente o desempenho organizacional - pode ser explicado pelo baixo nível de evidenciação pelos clubes de futebol, brasileiros e europeus sinalizado pela literatura (Maia; Vasconcelos, 2016; Maia, Rebouças, Vasconcelos, \& Reinaldo, 2018; Messias, Gallina, Ferreira, \& Zanchet, 2020), bem como enfatizado nos resultados destacados na subseção anterior, que indicou que a estrutura do futebol feminino dos clubes profissionais ainda encontra-se em transição do amadorismo para a sua profissionalização - o que pode comprometer a análise de sua influência no desempenho.

Cabe ressaltar que a legislação aplicável aos clubes analisados é bastante variada, tendo em vista a diversidade da amostra quanto ao país de origem. Em alguns mercados, como é o caso dos clubes ingleses, a maturidade e consequente profissionalização do futebol feminino é bem maior quando comparada aos demais países. A Inglaterra além de ser considerado o pioneiro do futebol masculino, destaca-se com a sua $3^{\mathrm{a}}$ posição no ranking da FIFA (UEFA, 2017), com seu pioneirismo quanto à profissionalização do futebol feminino.

Conforme observado na pesquisa, o relatório da UEFA (2017) revela que o futebol feminino inglês registrou crescimento de $12 \%$ em número de atletas e de 526 expectadores em presença do público nos principais jogos da liga nacional, desde 2013. Tais resultados vão ao encontro de Valenti, Scelles \& Morrow (2019), pois, esta crescente demanda de espectadores pode ajudar a criar vantagem competitiva sustentável, sinalizando a possível superação de um dos desafios estratégicos enfrentados no futebol feminino. Ademais, reduz o ceticismo sobre a possibilidade de o futebol se tornar financeiramente sustentável em um futuro próximo, conforme apontado por Allison (2016). Isto pode ser resultado de: investimentos na estrutura de liga nacional de Promoção e Rebaixamento (P\&R); orçamento anual de €15,447,385; patrocinadores comerciais específicos; categorias de ligas juvenis de sub-7 a sub-18; presença de mulheres assumindo posições de técnicas, árbitras, nível gerencial ou acima; e, respectivos comitês (UEFA, 2017).

Em alinhamento aos resultados desta pesquisa, é possível notar que a estrutura do futebol feminino dos clubes ingleses se destaca. Neste mercado, os clubes profissionais possuem uma empresa específica para o futebol masculino e uma empresa específica para o futebol feminino, apresentando relatórios financeiros independentes. Os resultados observados na pesquisa revelam que tais clubes não apenas investem no futebol feminino, mas possuem 
Maia, A. B. G. R., \& de Vasconcelos, A. C. (2022, jan./abr.). Ambiente institucional, estrutura do futebol feminino e desempenho de 61 clubes das ligas mais fortes do mundo

uma empresa própria para gerenciar o futebol feminino; assim, as informações sobre o futebol feminino permitem uma avaliação mais fidedigna do desempenho do clube de uma forma geral, bem como possibilitam prospectar cenários futuros.

Por outro lado, em outros mercados, como o argentino e brasileiro, o futebol feminino ainda está sendo maturado, transpondo o futebol amador para o futebol profissional. Assim, apesar de existirem muitas leis, normas e orientações técnicas, como por exemplo no Brasil, a Lei Pelé, a Lei do Profut, a ITG 2003 (R1) e a OTG 2003, que se aplicam às entidades desportivas de uma forma geral, não especificando a modalidade, os clubes ainda não estão apresentando informações específicas sobre as equipes femininas, seja quanto à Estrutura Física ou Estrutura Econômico-Financeira, como apresentado por alguns clubes europeus.

\section{Conclusões}

O presente estudo analisou os fatores que impulsionam a estrutura do futebol feminino e seu possível reflexo no desempenho dos clubes profissionais das ligas mais fortes do mundo. Para tanto, realizou-se uma pesquisa exploratória e quantitativa, com a aplicação de técnicas uni e multivariada, a partir do SPSS ${ }^{\circ}$.

Os resultados da análise fatorial indicaram três fatores a partir das cargas fatoriais das variáveis que mais impulsionam a estrutura do futebol feminino dos clubes, nomeados: (1) Pressão dos stakeholders (Endividamento, Hegemonia no futebol masculino e Torneios FIFA realizados); (2) Pressão por diversidade (Representatividade feminina na alta gestão, Confederação de vínculo e Internacionalização de atletas); (3) Tamanho do clube (Porte). Tal observação ratifica os pressupostos da teoria institucional que apontam que as organizações (no caso os clubes de futebol) podem ser afetados por diferentes atributos internos e pressões externas, o que confirma a primeira hipótese do estudo.

A aplicação da análise de clusters permitiu observar que os 61 clubes da amostra se agruparam em três clusters. O cluster 1 denominado Estrutura de futebol feminino madura, constituído por 18 clubes, com destaque aos clubes ingleses. O cluster 2 denominado Estrutura de futebol feminino em desenvolvimento, formado por 40 clubes, com destaque aos clubes brasileiros e argentinos. E, o cluster 3, denominado Estrutura de futebol feminino imatura, constituído por três clubes. É importante ressaltar que, quando suprimido a idade, destacam-se com melhor Estrutura Física do futebol feminino, respectivamente: o clube francês, Olympique 
Maia, A. B. G. R., \& de Vasconcelos, A. C. (2022, jan./abr.). Ambiente institucional, estrutura do futebol feminino e desempenho de 61 clubes das ligas mais fortes do mundo

Lyonnais; os clubes ingleses, Crystal Palace FC e Manchester City FC; e, o clube espanhol, RCD Espanyol.

Ademais, a análise de conteúdo dos relatórios financeiros e a estatística descritiva dos índices de estrutura de futebol feminino dos clubes indicaram que os clubes europeus possuem melhor estrutura de uma forma geral, mas ainda é incipiente a apresentação dos clubes profissionais no tocante às informações relacionadas à Estrutura Física e Estrutura EconômicoFinanceira do futebol feminino.

Por fim, quanto à estatística descritiva das variáveis de desempenho, observou-se que os clubes que possuíam equipe feminina em 2017-2018 obtiveram desempenho econômicofinanceiro (ROA e ROE) médio superior aos clubes que não possuíam. Contudo, os resultados do Teste-T sinalizaram que há diferenças significantes entre as médias do desempenho dos clubes com e sem equipe feminina apenas quanto à performance do capital humano - o que rejeita a segunda hipótese do estudo. Todavia, adverte-se que o baixo nível de evidenciação pelos clubes de futebol, brasileiros e europeus sinalizado pela literatura, bem como a incipiente estrutura do futebol feminino dos clubes profissionais observada na presente pesquisa, pode ter comprometido a análise de seu reflexo no desempenho dos clubes.

A contribuição conceitual desta pesquisa reside na busca de melhor entendimento da estrutura do futebol feminino dos clubes profissionais, bem como dos seus efeitos sobre o desempenho, visando a contribuir com evidências teórico-empíricas iniciais sobre esse ponto. Este trabalho se insere em uma linha de discussão até então inexplorada, haja vista não serem encontrados textos acadêmicos sobre a matéria em questão. Assim, estima-se potencial de contribuição quanto à: identificação de fatores institucionais que impulsionam a estrutura do futebol feminino dos clubes profissionais das ligas mais fortes do mundo; construção e categorização do índice de estrutura do futebol feminino; e, sinalização de reflexo no desempenho dos clubes, à luz da RBV.

Cabe ressaltar que por ser uma pesquisa exploratória, a presente pesquisa não tem a pretensão de exaurir o conhecimento sobre a temática, mas contribuir com evidências empíricas iniciais sobre essa questão, não sendo possível generalizar seus achados. Esta pesquisa centrou sua análise em apenas um período, temporada 2017-2018, tendo em vista que os dados da temporada mais recente ainda não estavam disponíveis na data de coleta de dados da pesquisa. Ademais, outra limitação do estudo faz alusão à concentração da análise quantitativa em função de dados secundários, pelo conjunto dos relatórios anuais contábil-financeiros auditados, dependendo das informações evidenciadas pelas entidades desportivas. Cabe ressaltar que, 
Maia, A. B. G. R., \& de Vasconcelos, A. C. (2022, jan./abr.). Ambiente institucional, estrutura do futebol feminino e desempenho de 61 clubes das ligas mais fortes do mundo

apesar do rigor metodológico adotado na pesquisa, os resultados foram obtidos a partir de uma amostra de clubes profissionais, em geral, com baixo nível de evidenciação, impactando diretamente a construção e categorização do índice de estrutura do futebol feminino, de modo que as conclusões não podem ser aplicadas a outros clubes. Não obstante a isso, segue uma abordagem predominantemente quantitativa, portanto algumas nuances não foram exploradas em função dessa escolha.

Como sugestões para pesquisas futuras, sugere-se a ampliação do escopo desta pesquisa, a partir da inclusão: dos demais clubes que foram ranqueados pelo IFFHS, incluindo outros níveis de ligas masculinas; das sucessivas temporadas, aumentando o número de observações; bem como, de outras variáveis que possam servir de análise para os fatores institucionais (ambiente institucional e pressões externas), como variáveis de governança corporativa, e ainda outras variáveis de desempenho, incluindo o desempenho desportivo. Ademais, sob outra perspectiva, pode-se empregar a abordagem fenomenológica, com a utilização de técnicas qualitativas que analisem outros tipos de documentos dos clubes, bem como das redes sociais, ou ainda a aplicação de entrevistas e survey, que poderia reduzir possíveis "ruídos" no tocante às inferências do presente estudo.

\section{Referências}

Allison, R. (2016). Business or cause? Gendered institutional logics in women's professional soccer. Journal of Sport and Social Issues, 40(3), 237-262.

Alves, C. (2019). Montar time feminino é exigência para equipes da Série A 2019: veja situação dos clubes. GloboEsporte.com [online]. Recuperado em 24 maio, 2019, de https://globoesporte.globo.com

Arakelian, J. S., Brito, E. Z., \& Rosenthal, B. (2020). The legitimation of global football brands in the Brazilian marketplace. InternexT - Revista Eletrônica de Negócios Internacionais da ESPM, 15(1), 104-117. http://dx.doi.org/10.18568/internext.v15i1.540

Balardin, G. F., Voser, R. C., Duarte Junior, M. A. S., \& Mazo, J. Z. (2018). O futebol feminino no Brasil e nos Estados Unidos. Revista Brasileira de Futsal e Futebol, 10(36), 101-109.

Barbosa, A., Dantas, M. G., Azevedo, Y., \& Holanda, V. (2017) Fiscal responsibility strategy in Brazilian football clubs: a dynamic efficiency analysis. Brazilian Business Review, 14 (Special Ed.), 45-66. https://doi.org/10.15728/edicaoesp.2017.3 
Maia, A. B. G. R., \& de Vasconcelos, A. C. (2022, jan./abr.). Ambiente institucional, estrutura do futebol feminino e desempenho de 61 clubes das ligas mais fortes do mundo

Barney, J. B. (1991). Firm resources and sustained competitive advantage. Journal of Management, 17(1), 99-120. https://doi.org/10.1177/014920639101700108

Benin, M. M. (2017). Eficiência econômica em clubes de futebol: um estudo com base na análise envoltória de dados. Tese de Doutorado, Universidade do Vale do Rio dos Sinos, Porto Alegre, RS, Brasil.

Coase, R. H. (1937). The nature of the firm. Economica, New Series, 4(16), 386-405. https://doi.org/10.1111/j.1468-0335.1937.tb00002.x

compliance. Journal of International Women's Studies, 16(3), 54-70.

Confederação Sul-Americana de Futebol. (2016) Regulamento de Futebol: licenças de clubes foi aprovado. Recuperado em 24 maio, 2019, de http://www.conmebol.com/

Confederação Sul-Americana de Futebol. (2020a) Conmebol suspende neste ano processo de licenças de clubes no futebol feminino como requerimento obrigatório para participar da Libertadores Feminina 2020. Recuperado em 21 dezembro, 2020, de http://www.conmebol.com/

Confederação Sul-Americana de Futebol. (2020b) Alejandro Domínguez: "Na Conmebol e no mundo o futuro tem que ser do futebol feminino". Recuperado em 21 dezembro, 2020, de http://www.conmebol.com/

Cortsen, K. (2016). 'Re-branding' women's football by means of a new Sports product: a case

Costa, G., \& Fonseca, J. P. (2019). No orçamento dos clubes, menos de $1 \%$ é para o feminino. Jornal O Globo [online]. Recuperado em 5 agosto, 2019, de https://oglobo.globo.com/

Costa, M. F., Costa, C. E., Angelo, C. F., \& Moraes, W. F. A. (2018). Perceived competitive advantage of soccer clubs. Revista de Administração, 53(1), 23-34.

https://doi.org/10.1016/j.rauspm.2016.08.001

Cousens, L., \& Slack, T. (2005). Field-level change: The case of North American major league professional sport. Journal of Sport Management, 19(1),13-42. https://doi.org/10.1123 / jsm.19.1.13

Das, A. (2016). Pay disparity in U.S. Soccer? It's complicated. The New York Times [online]. Recuperado em 22 junho, 2019, de https://www.nytimes.com/

Dezsö, C. L., \& Ross, D. G. (2012). Does female representation in top management improve firm performance?. Strategic Management Journal, 33(9), 1072-1089. https://doi.org/10.1002/smj.1955

Dias, I. R. \& Rossi, G. (2017). How far is World Champion from World Class? Institutional effects on a Brazilian non-profit sports organization. Brazilian Business Review, 14(ed. especial), 24-44. https://doi.org/10.15728/edicaoesp.2017.2 
Maia, A. B. G. R., \& de Vasconcelos, A. C. (2022, jan./abr.). Ambiente institucional, estrutura do futebol feminino e desempenho de 61 clubes das ligas mais fortes do mundo

Dimaggio, P. J., \& Powell, W. W. (1983) The iron cage revisited: institutional isomorphism and collective rationality in organizational fields. American Sociological Review, 48(2): 147-160. https://doi.org/10.2307/2095101

Dunn, C. (2016). Globalising women's football: Europe, migration and professionalization. Sport in History, 36(2), 251-253. https://doi.org/10.1080/17460263.2015.1008315

European Club Association. (2014). Women's Football Committee: women's club football analysis. Recuperado em 24 maio, 2019, de https://www.ecaeurope.com/

Faria, C. L. D. N., Dantas, M. G. D. S., \& Azevedo, Y. G. P. (2019). A influência dos fatores financeiros e esportivos sobre o valor dos clubes de futebol brasileiros. Revista Evidenciação Contábil \& Finanças, 7(1), 94-111. https://doi.org/10.22478/ufpb.23181001.0v0n0.37890

Fédération Internationale de Football Association. (2014). Women 's football survey. Recuperado em 24 maio, 2019, de https://www.fifa.com

Fédération Internationale de Football Association. (2016). FIFA 2.0: the vision for the future. Recuperado em 24 maio, 2019, de https://www.sportanddev.org/

Fédération Internationale des Associations de Footballeurs Professionnels. (2017). 2017 FIFPro global employment report: working conditions in professional women's football. Recuperado em 24 maio, 2019, de https://fifpro.org/

Feng, G., \& Jewell, T. (2018). Productivity and efficiency at English football clubs: a random coefficient approach. Scottish Journal of Political Economy, 1-34. https://doi.org/10.1111/sjpe.12178

Galbreath, J. (2018). Is board gender diversity linked to financial performance? The mediating mechanism of CSR. Business and Society, 57(5), 863-889. https://doi.org/10.1177/0007650316647967

Galvão, N. M. D. S., \& Dornelas, J. S. (2017). Análise de desempenho na geração de benefícios econômicos dos clubes de futebol brasileiros: o uso do atleta como recurso estratégico e ativo intangível. Revista Contemporânea de Contabilidade, 14(32), 2147. https://doi.org/10.5007/2175-8069.2017v14n32p21

Green, C. P., \& Homroy, S. (2018). Female directors, board committees and firm performance. European Economic Review, 102(C), 19-38. https://doi.org/10.1016 / j.euroecorev.2017.12.003

Hall, P. A., \& Soskice, D. (2015). An introduction to varieties of capitalism. In: Hall, P. A., Hartmann, J., \& Uhlenbruck, K. National institutional antecedents to corporate environmental performance. Journal of World Business, 50(4), 729-741.

Hallmann, K. (2012). Women's 2011 Football World Cup: the impact of perceived images of Hallmann, K., Oshimi, D., Harada, M., Matsuoka, H., \& Breuer, C. (2016). 'Spectators' point of attachment and their influence on behavioural intentions of women's national 
Maia, A. B. G. R., \& de Vasconcelos, A. C. (2022, jan./abr.). Ambiente institucional, estrutura do futebol feminino e desempenho de 61 clubes das ligas mais fortes do mundo

football games. Soccer \& Society, 1-21. https://doi.org/10.1080 / 14660970.2016.1267634

Herzog, M. (2018). The beginnings of women's football in south-western germany: from a spectacle to a sport event. In: Pfister, G., \& Pope, S. (eds.), Female Football Players and Fans, Football Research in an Enlarged Europe, 55-75.

International Federation of Football History \& Statistics. (2019) Club World Ranking 2018. Recuperado em 16 junho, 2019, de https://iffhs.de/

Januário, S. (2017). Marta em notícia: a (in)visibilidade do futebol feminino no Brasil. FuLiA / UFMG, 2(1), 28-43. https://doi.org/10.17851/2526-4494.2.1.28-43

Januário, S. B., Veloso, A. M. C., \& Cardoso, L. C. F. (2016). Mulher, mídia e esportes: a copa do mundo de futebol feminino sob a ótica dos portais de notícias pernambucanos. Eptic, 18(1), 168-184.

Klein, M. L. (2018). Women's football leagues in Europe: organizational and economic perspectives. In: Pfister, G.; Pope, S. (Eds). Female football players and fans (Chap. 5, pp. 77101). London: Palgrave Macmillan. https://doi.org/10.1057 / 978-1-137-59025$1 \_5$

Klein, M. W. (2004). Work and play: international evidence of gender equality in employment and sports. Journal of Sports Economics, 5(3), 227-242. https://doi.org/10.1177/1527002503257836

Knijnik, J. (2015). Femininities and masculinities in Brazilian women's football: resistance and

Kringstad, M. (2018). Is gender a competitive balance driver? Evidence from Scandinavian football. Cogent Social Sciences, 4(1), 1-15. https://doi.org/10.1080/23311886.2018.1439264

Lefeuvre, A. D., Stephenson, F. E., \& Walcott, S.M. (2013). Football frenzy: the effect of the 2011 World Cup on Women's Professional Soccer League attendance. Journal of Sports Economics, 14(4), 440-448. https://doi.org/10.1177/1527002513496012

Maia, A. B. G. R., \& Cardoso, V. I. C. (2019). In(eficiência) dos clubes de futebol mais fortes do mundo sob o enfoque da teoria institucional e variedades do capitalismo. Anais dos Seminários em Administração, SemeAD, São Paulo, SP, Brasil, 22. Recuperado em 3 março, 2020, de http://login.semead.com.br/22semead/anais/arquivos/583.pdf

Maia, A. B. G. R., \& Vasconcelos, A. C. (2016). Disclosure de ativos intangíveis dos clubes de futebol brasileiros e europeus. Contabilidade Vista \& Revista, 27(3), 1-31.

Maia, A. B. G. R., \& Vasconcelos, A. C. (2020). Futebol feminino nos clubes profissionais: fatores institucionais e reflexos no desempenho. Anais dos Seminários em Administração, SemeAD, São Paulo, SP, Brasil, 23. Recuperado em 22 janeiro, 2022, de https://login.semead.com.br/23semead/anais/arquivos/1344.pdf 
Maia, A. B. G. R., \& de Vasconcelos, A. C. (2022, jan./abr.). Ambiente institucional, estrutura do futebol feminino e desempenho de 61 clubes das ligas mais fortes do mundo

Maia, A. B. G. R., Rebouças, A. J. S., Vasconcelos, A. C., \& Reinaldo, L. M. (2018). Governança e desempenho nos clubes brasileiros de futebol. Anais do USP International Conference in Accounting, São Paulo, SP, Brasil, 18. Recuperado em 21 junho, 2019, de https://congressousp.fipecafi.org/anais/18UspInternational/ArtigosDownload/1042.pdf

Markovits, A. S., \& Hellerman, S. L. (2003). Women's soccer in the United States: yet another american 'exceptionalism'. Soccer \& Society, 4(2-3), 1429. https://doi.org/10.1080/14660970512331390805

Martins, V., Marquezan, L., Diehl, C., \& Flores, J. (2017). Alta especificidade de ativos na avaliação dos custos de transação. Revista Universo Contábil, 13(2), 130-148. https://doi.org/10.4270/RUC.2017212

Mayer, R., Martins, V. Q., \& Kronbauer, C. A. (2018). A evidenciação de informações contábeis obrigatórias e voluntárias: um estudo em clubes de futebol brasileiros. Anais do Congresso Brasileiro de Custos, Vitória, ES, Brasil, 25. Recuperado em 21 junho, 2019, de https://anaiscbc.emnuvens.com.br/anais/article/view/4421

McLachlan, F. (2019). It's boom time! (again): progress narratives and women's sport in Australia. Journal of Australian Studies, 43(1), 7-21. https://doi.org/10.1080/14443058.2019.1575262

Meier, H. E., \& Leinwather, M. (2012). Women as 'armchair audience'? Evidence from German national team football. Sociology of Sport Journal, 29(3), 365-384. https://doi.org/10.1123 / ssj.29.3.365

Messias, D., Gallina, A. S., Ferreira, J. C., \& Zanchet, A. (2020). 'Impairment test' em jogadores de futebol: análise dos Trigger events que justificam a realização do teste de recuperabilidade em atletas profissionais. Revista de Administração, Contabilidade e Economia da FUNDACE, 11(1), 80-94. http://dx.doi.org/10.13059/racef.v11i1.659

Meyer, J. W., \& Rowan, B. (1977). Institutionalized organizations: formal structure as myth and ceremony. American Journal of Sociology, 83, 340-363.

Nascimento, J. C. H. B., Nossa, V., Bernardes, J. R., \& Sousa, W. D. (2015). A eficiência dos maiores clubes de futebol brasileiros: evidências de uma análise longitudinal no período de 2006 a 2011. Contabilidade Vista \& Revista, 26(2), 137-161.

North, D. (1990). Institutions, institutional change, and economic performance. Cambridge: Cambridge University Press.

Penrose, E. T. (1959). The theory of the growth of the firm. New York: Wiley.

Pereira, A. G. C., Brunozi Junior, A. C., Kronbauer, C. A., \& Abrantes, L. A. (2015). Eficiência técnica e desempenho econômico-financeiro dos clubes de futebol brasileiros. Reuna, 20(2), 115-138. 
Maia, A. B. G. R., \& de Vasconcelos, A. C. (2022, jan./abr.). Ambiente institucional, estrutura do futebol feminino e desempenho de 61 clubes das ligas mais fortes do mundo

Pyatunina, A. V., Vishnyakova, A. B., Sherstneva, N. L., Mironova, S. P., Dneprov, S. A. \& Grabozdinc, Y. P. (2016). Recuperado em 21 junho, 2019, de The economic efficiency of European football clubs: Data Envelopment Analysis (DEA) approach.

International Journal of Environmental and Science Education, 11(15), 7515-7534.

Radnedge, K. (2009). Recordes do futebol mundial. São Paulo: Martin Corteel.

Review, 15(1), 33-42. https://doi.org/10.1016 / j.smr.2011.05.002

Ricci, F., Scafarto, V., Celenza, D., \& Gilvari, I. D. (2015). Intellectual capital and business performance in professional football clubs: evidence from a longitudinal analysis. Journal of Modern Accounting and Auditing, 11(9), 450-465. https://doi.org/10.17265 / 1548-6583 / 2015.09.003

Rizzo, M. (2020). Fifa quer Mundial de Clubes feminino para minar motim de Uefa e Conmebol. UOL Esporte [online]. Recuperado em 25 abril, 2020, de https://www.uol.com.br/

Rohde, M., \& Breuer, C. (2018). Competing by investments or efficiency? Exploring financial and sporting efficiency of club ownership structures in European football. Sport Management Review, 21(5), 563-581. https://doi.org/10.1016 / j.smr.2018.01.001

Rottenberg, S. (1956). The baseball player's labor market. Journal of Political Economy, 64(3), 242-258. http://dx.doi.org/10.1086/257790

Rumelt, R. P. (1984). Foreword. In: Hamel, G., \& Heene, A. (1984). Competence-based competition. New York: John Wiley.

Sardinha, E. M. (2011). A estrutura do futebol feminino no Brasil. Revista Hórus, 6(1), 92110.

Schaefer, J. L., Fagundes, B. J., Moraes, J., Nara, E. O. B., \& Kothe, J. V. (2019). Aplicação de métodos multicritérios para ordenação e comparação da eficiência financeira dos clubes de futebol do campeonato brasileiro de futebol da série A. Revista Brasileira de Futsal e Futebol, 11(42), 31-43.

Schallhorn, C., Knoll, J., \& Schramm, H. (2017). 'Girls just want to have fun?' Sex differences in motives of watching the FIFA World Cup and the UEFA European Championship. Sport in Society, 20(9), 1118-1133. https://doi.org/10.1080 / 17430437.2016.1269079

Scott, R. (1995). Institutions and organizations. Thousand Oaks, CA: Sage.

Scully, G. W. (1974). Pay and performance in major league baseball. American Economic Review, 64(6), 915-930.

Selznick, P. (1948). Foundations of the Theory of Organization. American Sociological Review, 13(1), 25-35. https://doi.org/10.2307/2086752 
Maia, A. B. G. R., \& de Vasconcelos, A. C. (2022, jan./abr.). Ambiente institucional, estrutura do futebol feminino e desempenho de 61 clubes das ligas mais fortes do mundo

Siqueira, J. P. L., Pajanian, F., \& Telles, R. (2015). Identificação e categorização dos stakeholders de um clube de futebol profissional brasileiro. Revista Ibero-Americana de Estratégia, 14(3), 15-31.

Slack, T. (1994). Theoretical diversity and the study of sport organizations. International Review for the Sociology of Sport, 29(3), 239-242. https://doi.org/10.1177/101269029402900301

study of women's football in Denmark. Soccer \& Society, 18(7), 1058-1079. https://doi.org/10.1080/14660970.2015.1133410

Szymanski, M., Fitzsimmons, S. R., \& Danis, W. M. (2019). Multicultural managers and competitive advantage. International Business Review, 28(2), 305-315. https://doi.org/10.1016 / j.ibusrev.2018.10.003

Terjesen, S, Aguileta, R. V., \& Lorenz, R. (2015). Legislating a woman's seat on the board: institutional factors driving gender quotas for boards of directors. Journal Business Ethics, 128(1), 223-251. https://doi.org/10.1007/s10551-014-2083-1

Torgler, B. (2008). The determinants of women's international soccer performances. International Journal of Sport Management and Marketing, 3(4), 305-318. https://doi.org/10.2139 / ssrn.680502

Torres, I. (2019). Why the 2019 Women's World Cup is opening eyes, and breaking records. Recuperado em 5 julho, 2019, de https://news.abs-cbn.com/

Union of European Football Associations. (2017). Women's football across the national associations 2017. Recuperado em 1 março, 2020, de https://preview.thenewsmarket.com/

United Nations. (2018). World economic situation and prospects 2018. Recuperado em 5 julho, 2019, de https://www.un.org/

Valenti, M., Scelles, N., \& Morrow, S. (2019) The determinants of stadium attendance in elite women's football: evidence from the UEFA Women's Champions League. Sport Management Review, 23(3), 509-520. https://doi.org/10.1016/j.smr.2019.04.005

Wernerfelt, B. (1984). A resource-based view of the firm. Strategic Management Journal, 5(2), 171-180. https://doi.org/10.1002/smj.4250050207

Williamson, O. (1985). The economic institutions of capitalism. New York: FreePress.

women's soccer and the World Cup 2011 on interest in attending matches. Sport Management Woodward, K. (2017). Women's time?. Sport in Society, 20(5-6), 689-700. https://doi.org/10.1080/17430437.2016.1158471

$\mathrm{Xu}, \mathrm{W}$. (2018). Operational efficiency of the football team in Chinese super league with DEA. Electronic Business Journal, 17(5), 9-17. https://doi.org/10.5539 / ibr.v11n3p1 